\title{
Evaluating the performance of aggregate production planning strategies under uncertainty in soft drink industry
}

DOI:

10.1016/j.jmsy.2018.12.009

\section{Document Version}

Accepted author manuscript

Link to publication record in Manchester Research Explorer

\section{Citation for published version (APA):}

Jamalnia, A., Yang, J., Xu, D., Feili, A., \& Jamali, G. (2019). Evaluating the performance of aggregate production planning strategies under uncertainty in soft drink industry. Journal of Manufacturing Systems, 50, 146-162. https://doi.org/10.1016/j.jmsy.2018.12.009

\section{Published in:}

Journal of Manufacturing Systems

\section{Citing this paper}

Please note that where the full-text provided on Manchester Research Explorer is the Author Accepted Manuscript or Proof version this may differ from the final Published version. If citing, it is advised that you check and use the publisher's definitive version.

\section{General rights}

Copyright and moral rights for the publications made accessible in the Research Explorer are retained by the authors and/or other copyright owners and it is a condition of accessing publications that users recognise and abide by the legal requirements associated with these rights.

\section{Takedown policy}

If you believe that this document breaches copyright please refer to the University of Manchester's Takedown Procedures [http://man.ac.uk/04Y6Bo] or contact uml.scholarlycommunications@manchester.ac.uk providing relevant details, so we can investigate your claim.

\section{OPEN ACCESS}




\title{
Evaluating the performance of aggregate production planning strategies under uncertainty in soft drink industry
}

\author{
Aboozar Jamalnia ${ }^{\mathrm{a} *}$, Jian-Bo Yang ${ }^{\mathrm{b}}$, Dong-Ling $\mathrm{Xu}^{\mathrm{b}}$, Ardalan Feili, ${ }^{\mathrm{c}}$, Gholamreza Jamali ${ }^{\mathrm{d}}$ \\ ${ }^{a}$ Operations Management and Information Technology Department, Faculty of Management, Kharazmi University, Tehran, \\ Iran. \\ ${ }^{\mathrm{b}}$ Decision and Cognitive Sciences Research Centre, Alliance Manchester Business School, The University of Manchester, \\ Manchester, United Kingdom. \\ ${ }^{c}$ School of Management, Ferdowsi University of Mashhad, Mashhad, Iran. \\ ${ }^{d}$ Department of Industrial Management, Faculty of Humanities, Persian Gulf University, Bushehr, Iran. \\ "Corresponding author. Tel.: +989365025148. \\ Email addresses: aboozar.jamalnia@gmail.com (A. Jamalnia).
}

Abstract: The present study is to evaluate the performance of different aggregate production planning (APP) strategies in presence of uncertainty. Therefore, the relevant models for APP strategies including the pure chase, the pure level, the modified chase, the modified level and the mixed chase and level strategies are constructed by using both multi-objective programming and simulation methods. The models constructed for these strategies are run with respect to the corresponding objectives/criteria in order to provide business insights to operations managers about the effectiveness and practicality of various APP strategies in presence of uncertainty. The real world operational data are collected from soft drink industry to validate and implement the models.

In addition, multiple criteria decision making (MCDM) methods are used besides multi-objective optimisation to assess the overall performance of each APP strategy. A detailed sensitivity analysis is also conducted by changing the criteria weights in MCDM methods to evaluate the impacts that these weight changes can have on the final rank of each APP strategy.

The results of the simulation models are compared to those of multi-objective optimisation models. In general, in both mathematical programming and simulation models, the pure chase and the modified chase strategies presented the best performance, followed by the pure level strategy.

Keywords: Aggregate production planning (APP) strategies; Uncertainty; Multi-objective optimisation; Simulation.

\section{Introduction}

\subsection{General overview}

Aggregate production planning (APP) is a medium range production and employment planning that normally spans a time horizon which ranges from 3 to 18 months and is about determining the 
optimum production quantities, hiring and lay off rates, work force and inventory levels, backordering and subcontracting volumes, and so on for each time period within the planning horizon subject to the limitations of available production resources. Such planning technique typically involves one product or a family of similar products, i.e. products with similarities in production process, skills required, materials needed, etc. despite minor differences so that considering the problem from an aggregated viewpoint is still valid.

APP has attracted considerable attention from both practitioners and academia (Shi \& Haase, 1996). Since 1955 that the pioneering studies by Holt et al. (1955) and Holt et al. (1956) proposed linear decision rule, and Bowman (1956) suggested transportation method to deal with APP, researchers have developed different methodologies to handle the APP problem.

Figure 1 outlines the APP position among other types of production planning and control techniques, and their interconnected relationships from a holistic perspective. As can be seen from the Figure 1, in the hierarchy of production planning and control activities, APP falls between long-term strategic planning decisions such as new product development and short term shop floor scheduling practices.

The forecasted demand acts as the driving force of the APP system. Seasonal demand patterns together with unpredictability inherent in quantity and timing of received orders makes the whole APP system uncertain, which in turn recommends utilising a decision modelling tool that takes account of these uncertainties.

As such, due to the dynamic nature of APP and instable states of real world industrial environments, the deterministic models for APP would lead to unrobust decisions. Moreover, similar to other production planning family members, APP also involves several objectives/criteria in practice.

Therefore, the present study utilises a novel stochastic, nonlinear, multi-stage, multi-objective decision making model of APP which considers multiple objectives such as total revenue, total production costs, total labour productivity costs, total costs of the changes in workforce level and customer satisfaction subject to bounds on inventory, backorder, subcontracting, workforce level, and so forth under uncertainty.

In the first phase, the comprehensive stochastic, nonlinear, multi-objective mathematical programming model of APP which was developed in our previous research, under the primary mixed chase and level strategy subject to demand uncertainty, is reconsidered. WWW-NIMBUS software (Miettinen and Mäkelä, 2006) will be used to solve this stochastic, nonlinear, nonconvex, nonsmooth, non-differentiable, multi-objective optimisation model of the APP problem.

Then, the relevant models for other APP strategies including the pure chase, the pure level, the modified chase and the modified level are derived from the fundamental model developed for the 
mixed chase and level strategy. The same procedure, as described above, follows to solve the models constructed for these strategies with respect to the aforementioned objectives/criteria to provide managerial and business insights for operations managers about the effectiveness and usefulness of various APP policies.

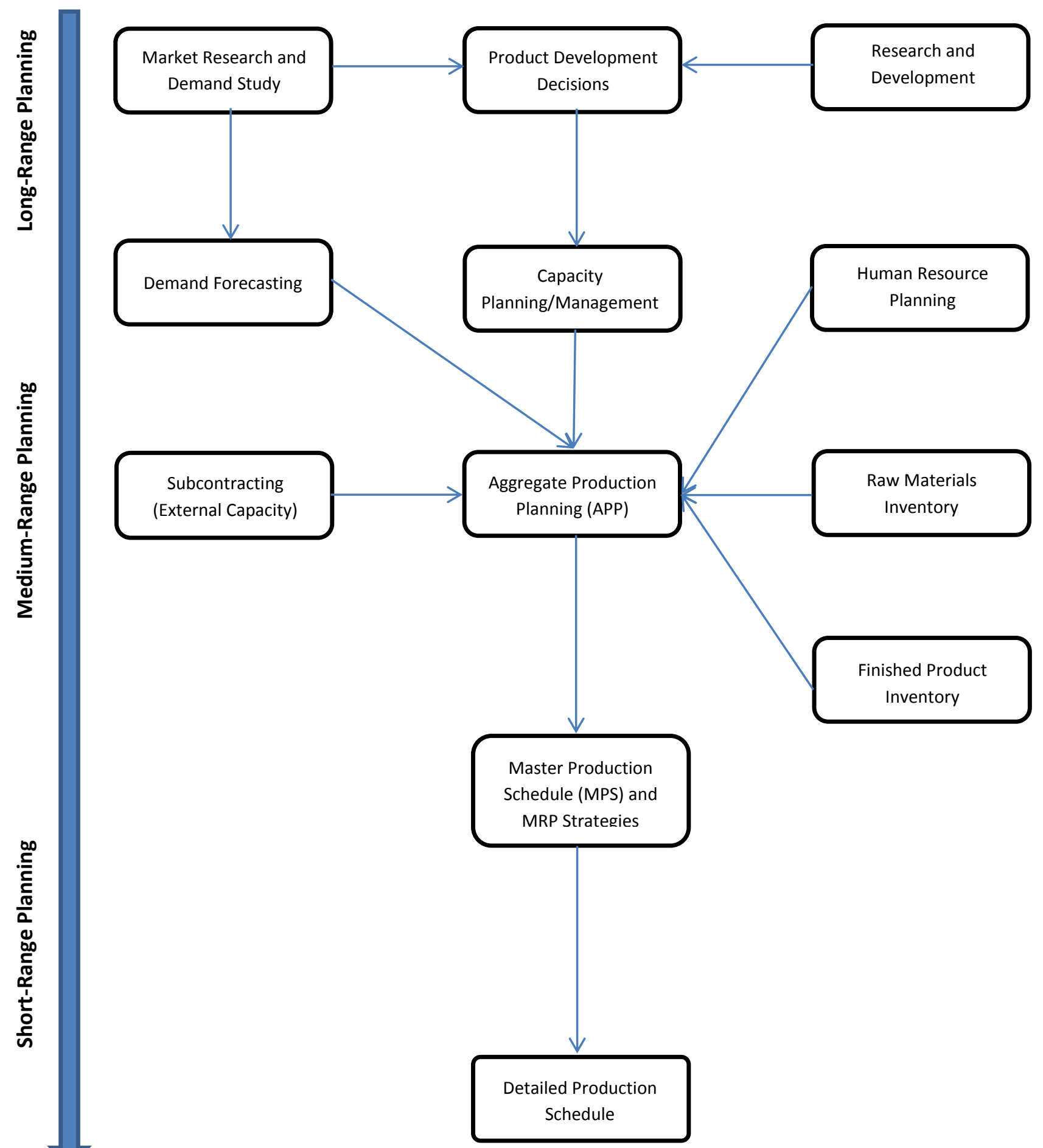

Figure 1: The diagram which shows APP relationships with other types of production planning and control activities (Jamalnia et al., 2019) 
Additive value function (AVF), the technique for order of preference by similarity to ideal solution (TOPSIS) and VIKOR, as multiple criteria decision making (MCDM) methods, are also utilised in addition to multi-objective optimisation to evaluate the overall performance of each APP plan.

An integrated discrete event simulation (DES) and system dynamics (SD) modelling of APP strategies is also presented, and the results are compared to those of mathematical models.

The paper is further organised as follows. In the next two parts the regular APP options and policies are explained, and then the problem under study is described. Section 2 briefly reviews the most relevant literature; the research gaps and contributions of the present study are also presented in this section. In Section 3, mathematical models are developed, and run for different APP strategies. In Section 4, APP strategies are analysed in detail by applying MCDM methods and conducting sensitivity analysis, together with simulating APP strategies and comparing its results with those of mathematical programming. Finally the conclusions and possible future research extensions are presented in Section 5.

\subsection{Common APP strategies}

Three basic operations strategies can be used in APP, along with many combinations in between, to meet the fluctuating demand over time. One basic strategy is to level the workforce; the other is to chase demand with the workforce. With a perfectly level strategy, the rate of regular time output will be constant. Any variations in demand must then be absorbed using inventories, overtime, temporary workers, subcontracting, backorders or any of the demand-influencing options. With the chase strategy, the workforce level is changed to meet, or chase, demand. In this case, it is not necessary to carry inventory or to use any of the other variables available for APP; the workforce absorbs all the changes in demand (Reid and Sanders, 2009; Schroeder, 2003). The third strategy, the pure demand management strategy, is an approach that attempts to change or influence demand to fit available capacity by employing options such as pricing, advertising and developing alternative products and services (Slack, Brandon-Jones and Johnston, 2013).

Normally, the pure demand management policy is always considered as part of the level strategy. The present research also regards the demand management policy as a subset of level strategy.

Each of the two pure plans is applied only where its advantages strongly outweigh its disadvantages. For many organisations, however, these pure approaches do not match their required combination of competitive and operational objectives. Most operations managers are required simultaneously to reduce costs and inventory, to minimise capital investment and yet to provide a responsive and costumer-oriented approach at all times. For this reason, most organisations choose to follow a mixture of the two approaches (Slack, Brandon-Jones and Johnston, 2013). 


\subsection{Problem statement}

The industrial data was collected from ZamZam Group as a major soft drink manufacturing company in West Asia. As the former PepsiCo subsidiary in Iran, the company then changed its trade name to ZamZam and was expanded from one plant to seventeen plants all over the country and the Middle East. The Group produces a diverse set of over a hundred products which range from beverages to beers and mineral waters.

The company under study, ZamZam Shiraz as a member of ZamZam Group, normally operates in two 8 hour shifts. Shift 1 basically finishes at $4 \mathrm{pm}$ every day, and then shift 2 starts which are respectively called regular shift and extra shift by the operations management department of the company. The shifts are considered separately because of costs differences, e.g. wage costs in extra shift are higher.

ZamZam Isfahan, another branch of the ZamZam Group in city of Isfahan, Iran, usually produces the subcontracts. Backorders should be met by the next time period at the latest. The product demand follows a seasonal pattern, i.e. in spring and summer demand rises, and in autumn and winter demand declines.

The company hires and lays off the workers, mostly lower skilled workers, according to changes in demand level. The newly hired workers go through a short training process.

The production planners implement APP mainly by using linear programming and simulation methods alongside their experience.

The seasonal demand pattern in soft drink industry and also co-production within ZamZam Group by subsidiary plants (which makes options such as subcontracting practically possible) makes the Company a perfectly suitable case study for current research.

There are a lot of similarities in production process, used raw materials and human resource skills and in nature and amount of related production, procurement, salary and hiring/lay off costs for soft drink and beverage products. Additionally, considering the seasonality of demand for these products and sensitivity of their demand to pricing and advertising policies make generalisation of the findings of present research in soft drink and beverage industry reasonable.

As already mentioned in Section 1.1, the APP is usually implemented for a family of similar products. As such, the carbonated soft drinks in $300 \mathrm{ml}$ bottles in three flavours cola, orange and lemonade are classified as a family of products in order to conduct APP process. The developed mathematical model for multiproduct APP decision making problem covers a time horizon of 12 months which includes 4 time periods, i.e. 4 seasons to reflect the seasonal fluctuations in the product demand. The constructed simulation model considers 12 time periods (time steps) but demand, production, 
employment and materials supply rates are averaged over 3 month periods to reflect the seasonality of demand.

The market demand is supposed to be the main source of uncertainty and is presented in terms of three demand level scenarios: high demand, average demand and low demand with associated probabilities which are abbreviated as $H, A$ and $L$ respectively throughout the study.

The present research objective is to appraise different APP strategies' performance under uncertainty. Main research question is: which APP strategies are more effective and useful with regard to relevant criteria under uncertainty?

\section{Background}

\subsection{Literature on multi-objective optimisation to APP under uncertainty}

\subsubsection{Stochastic multi-objective optimisation of APP under uncertainty}

Rakes, Franz and Wynne (1984), Chen and Liao (2003), Mezghani, Loukil and Aouni (2011), Nowak (2013), Jamalnia et al. (2017) utilised stochastic multi-objective optimisation techniques to consider APP under uncertainty.

Mezghani, Loukil and Aouni (2011) developed a goal programming model for APP where the goals and the right-hand sides of constraints are random and normally distributed variables. Nowak (2013) presented a procedure which combines linear multi-objective programming, simulation and an interactive approach to model APP with uncertain demand. Jamalnia et al. (2017) proposed a novel decision model for APP based on mixed chase and level strategy under uncertainty where the market demand is regarded as the main source of uncertainty. Ultimately, their constructed model turns out to be stochastic, nonlinear, multi-stage and multi-objective.

\subsubsection{Fuzzy multi-objective optimisation of APP under uncertainty}

Since APP problem always involves several criteria (objectives) and due to the vagueness of the available information, fuzzy multi-objective programming has been widely used in this area.

Lee (1990), Gen, Tsujimura and Ida (1992), Wang and Fang (2001), Wang and Liang (2004), Ghasemy Yaghin, Torabi and Fatemi Ghomi (2012), Madadi and Wong (2014), Gholamian et al. (2015), Gholamian, Mahdavi and Tavakkoli-Moghaddam (2016), Kalaf et al. (2015), Sisca, Fiasché and Taisch (2015), Fiasché et al. (2016) and Zaidan et al. (2017) utilised various kinds of fuzzy multi-objective optimisation models to study APP under uncertainty.

Gholamian et al. (2015) and Gholamian, Mahdavi and Tavakkoli-Moghaddam (2016) developed a fuzzy multi-site multi-objective mixed integer nonlinear APP model in a supply chain under uncertainty with fuzzy demand, fuzzy cost parameters, etc. A modified fuzzy multi-objective linear 
programming method to APP that minimises total production costs and total labour costs is proposed by Kalaf et al. (2015), which involves fuzzy aspiration levels of the objectives and fuzzy tolerance levels.

Sisca, Fiasché and Taisch (2015) constructed a fuzzy multi-objective linear programming model for APP in a reconfigurable assembly unit for optoelectronics where product price, inventory cost, etc. are supposed to be fuzzy variables. Fiasché et al. (2016) developed a fuzzy linear multi-objective optimisation model of APP in fuzzy environment where the product price, unit cost of not utilising the resources, etc. are of fuzzy nature. Zaidan et al. (2017) proposed a hybridisation of a fuzzy programming, simulated annealing (SA), and simplex downhill (SD) algorithm called fuzzy SASD to establish multiple-objective linear programming models and consequently solve APP problems in a fuzzy environment so that operating costs, data capacities and forecast demand are assumed to be fuzzy.

\subsection{Literature on appraising APP policies}

The studies on evaluating the relevant APP policies which range from surveys to quantitative management science-based methods include Lee and Khumawala (1974), Dubois and Oliff (1991), Buxey (1990, 1995, 2003, 2005), Thompson, Wantanabe, and Davis (1993), Chen and Liao (2003), Gulsun et al. (2009), Liao, Chen and Chang (2011) and Jamalnia and Feili ( 2013).

Through simulating the activities of an operating firm, Lee and Khumawala (1974) assessed the performance of four different APP policies under demand uncertainty. Dubois and Oliff (1991) surveyed a cross section of manufacturers about present practices of APP. Using input from practitioners and academicians a questionnaire was developed to examine strategies that the firm uses to deal with short range and long range demand fluctuations, major inputs to APP decisions, etc.

Buxey $(1990,1995,2003,2005)$ conducted surveys in groups of Australian firms in different industries to find out which APP policies are the most widely used in practice.

Thompson, Wantanabe, and Davis (1993) developed linear programming frameworks to evaluate several APP policies where customer demand, most of the coefficients of the linear programming model and some parameters were presented with probability distributions to reflect the uncertainty in APP environment. Chen and Liao (2003) adopted a multi-attribute decision making approach to select the most efficient APP strategy such that selling price, market demand, cost coefficients, etc. are assumed to be stochastic variables.

Liao, Chen and Chang (2011) applied a simulation method to simulate the six different APP's strategies to further evaluate the results of multiple objectives, including total cost, average service 
level and average changes in production rate. They used the TOPSIS and fuzzy linguistic methods to compare the different weights of different objectives to obtain the optimal APP strategy selection sequence for decision-makers in hospital supply chain management.

Gulsun et al. (2009) developed a deterministic multi-objective optimisation model for APP which is used as a basis to select the most appropriate APP strategy. Jamalnia and Feili (2013) employed an integrated system dynamics and discrete-event simulation approach in order to evaluate the effectiveness and practicality of different APP strategies on the basis of total profit measure, where the market demand was regarded as random variable.

\subsection{Research gaps in the literature}

The existing research on APP strategies/policies assessment mainly has the following drawbacks:

a) The APP methods examined by earlier studies on APP, such as linear decision rule (LDR), search decision rule (SDR) and management coefficient model (MCM), used to be among the rudimentary methodologies proposed to deal with APP, and they are currently regarded as conventional approaches to handle APP decision process that are no longer in use or are used very rarely. The newer trends in the past decades on developing novel approaches and methodologies to deal with APP demand utilising corresponding state of the art APP policies.

b) Studies that use surveys to get insight on most popular APP policies in practice also have drawbacks in common, mainly:

These studies were surveys in specific geographical areas, and their results only indicate the popularity of using relevant APP policies/strategies from the respondents' viewpoints, e.g. from operations managers viewpoints in those geographical places, while the APP strategies employed by the industry managers may not necessarily be the optimal ones.

In addition, these categories of studies provide results that can hardly be generalised to other geographical locations.

Finally, the results have not been achieved by using an efficient analytical method based on suitable criteria, and only present managers' responses on most widely used APP policies.

\subsection{The contributions of present research}

We have adopted up to date APP strategies from a wide variety of relevant literature, instead of old APP methods such as LDR, SDR and MCM, and have done a detailed analysis of their performance which would be of interest to readers who are interested in contemporary operations management issues. Almost all contemporary literature of operations management, consider chase, level, and 
their combination as popular strategies of APP (or sales \& operations planning (S\&OP) as the new terminology) which is followed by this study as well.

Unlike the studies that have conducted surveys to find out most popular APP policies in real world industrial environments, the analytical management science methods applied in present research give the operations managers more robust quantified measures on which APP strategies have better performance regarding different criteria since popularity of a given APP strategy in practice does not necessarily mean it is the most efficient as well.

Apart from precise advertising, pricing and recruiting mechanisms which are included in constructed APP models, a wide range of criteria ( 8 criteria) are considered in examining the performance of each APP strategy. Moreover, APP in practice involves stochasticity, nonlinearity and multiobjectivity. The existing APP literature includes one or two of these features at most for the sake of simplicity. For the first time, this study presents APP models that deals with these three attribute all together under the same framework to represent a holistic picture of APP.

Additionally, the breadth of collected data from ZamZam Group which includes over 17 branches in West Asia with wide variety of soft drink products, similarity of production process and also similarity in used raw materials and human resource skills and in nature and amount of production, procurement, salary and hiring/lay off costs, seasonality of demand for almost all drink products and their similar demand pattern which is especially highly sensitive to pricing and advertising policies make generalising the findings of the current research at least in soft drink and beverage industry more valid.

A comparison between present study and existing research on appraising the APP policies is presented in Table 1. 
Table 1: Comparison between the studies on evaluation of the APP strategies

\begin{tabular}{|c|c|c|c|c|c|c|c|c|c|}
\hline & $\begin{array}{l}\text { Buxey } \\
(1990, \\
1995, \\
2003, \\
2005)\end{array}$ & $\begin{array}{l}\text { Dubois and } \\
\text { Oliff (1991) }\end{array}$ & $\begin{array}{c}\text { Lee and } \\
\text { Khumawala } \\
(1974)\end{array}$ & $\begin{array}{c}\text { Thompson, } \\
\text { Wantanabe, } \\
\text { and Davis } \\
\text { (1993) }\end{array}$ & $\begin{array}{l}\text { Chen and } \\
\text { Liao (2003) }\end{array}$ & $\begin{array}{l}\text { Gulsun et al. } \\
\text { (2009) }\end{array}$ & $\begin{array}{c}\text { Liao, Chen } \\
\text { and Chang } \\
(2011)\end{array}$ & $\begin{array}{l}\text { Jamalnia and } \\
\text { Feili ( 2013) }\end{array}$ & $\begin{array}{c}\text { The present } \\
\text { study }\end{array}$ \\
\hline Type of study & $\begin{array}{l}\text { Empirical } \\
\text { research } \\
\text { by using } \\
\text { survey }\end{array}$ & $\begin{array}{l}\text { Empirical } \\
\text { research } \\
\text { by using } \\
\text { survey }\end{array}$ & $\begin{array}{l}\text { Analytical } \\
\text { modelling }\end{array}$ & $\begin{array}{l}\text { Analytical } \\
\text { modelling }\end{array}$ & $\begin{array}{l}\text { Analytical } \\
\text { modelling }\end{array}$ & $\begin{array}{l}\text { Analytical } \\
\text { modelling }\end{array}$ & $\begin{array}{l}\text { Analytical } \\
\text { modelling }\end{array}$ & $\begin{array}{l}\text { Analytical } \\
\text { modelling }\end{array}$ & $\begin{array}{l}\text { Analytical } \\
\text { modelling }\end{array}$ \\
\hline $\begin{array}{c}\text { Changing } \\
\text { workforce level }\end{array}$ & $\begin{array}{c}\text { Not } \\
\text { applicable }\end{array}$ & $\begin{array}{c}\text { Not } \\
\text { applicable }\end{array}$ & Considered & $\begin{array}{c}\text { Not } \\
\text { considered }\end{array}$ & $\begin{array}{c}\text { Not } \\
\text { considered }\end{array}$ & Considered & $\begin{array}{c}\text { Not } \\
\text { considered }\end{array}$ & Considered & Considered \\
\hline $\begin{array}{l}\text { Changing } \\
\text { production } \\
\text { capacity }\end{array}$ & $\begin{array}{c}\text { Not } \\
\text { applicable }\end{array}$ & $\begin{array}{c}\text { Not } \\
\text { applicable }\end{array}$ & $\begin{array}{c}\text { Performed } \\
\text { by } \\
\text { changing } \\
\text { workforce } \\
\text { level and } \\
\text { overtime }\end{array}$ & $\begin{array}{l}\text { Performed } \\
\text { by using } \\
\text { overtime }\end{array}$ & $\begin{array}{l}\text { Performed } \\
\text { by using } \\
\text { overtime }\end{array}$ & $\begin{array}{l}\text { Performed by } \\
\text { changing } \\
\text { workforce } \\
\text { level, } \\
\text { overtime and } \\
\text { subcontracting }\end{array}$ & $\begin{array}{l}\text { Performed } \\
\text { by using } \\
\text { overtime }\end{array}$ & $\begin{array}{l}\text { Performed by } \\
\text { changing } \\
\text { workforce } \\
\text { level, } \\
\text { overtime and } \\
\text { subcontracting }\end{array}$ & $\begin{array}{l}\text { Performed by } \\
\text { changing } \\
\text { workforce } \\
\text { level, extra } \\
\text { shift/overtime } \\
\text { and } \\
\text { subcontracting }\end{array}$ \\
\hline Subcontracting & $\begin{array}{c}\text { Not } \\
\text { applicable }\end{array}$ & $\begin{array}{c}\text { Not } \\
\text { applicable }\end{array}$ & $\begin{array}{c}\text { Not } \\
\text { considered }\end{array}$ & $\begin{array}{c}\text { Not } \\
\text { considered }\end{array}$ & $\begin{array}{c}\text { Not } \\
\text { considered }\end{array}$ & considered & $\begin{array}{c}\text { Not } \\
\text { considered }\end{array}$ & Considered & Considered \\
\hline $\begin{array}{l}\text { APP strategies } \\
\text { modelled } \\
\text { (surveyed) }\end{array}$ & $\begin{array}{l}\text { All } \\
\text { common } \\
\text { APP } \\
\text { strategies }\end{array}$ & $\begin{array}{c}\text { Some } \\
\text { forms of } \\
\text { chase and } \\
\text { level } \\
\text { strategies }\end{array}$ & $\begin{array}{l}\text { Linear } \\
\text { decision } \\
\text { rule, search } \\
\text { decision } \\
\text { rule, etc. }\end{array}$ & $\begin{array}{l}\text { Some forms } \\
\text { of chase } \\
\text { and level } \\
\text { strategies }\end{array}$ & $\begin{array}{c}\text { Some } \\
\text { forms of } \\
\text { chase and } \\
\text { level } \\
\text { strategies }\end{array}$ & $\begin{array}{l}\text { Some forms of } \\
\text { chase and } \\
\text { level } \\
\text { strategies }\end{array}$ & $\begin{array}{c}\text { Some } \\
\text { forms of } \\
\text { chase and } \\
\text { level } \\
\text { strategies }\end{array}$ & $\begin{array}{l}\text { All common } \\
\text { APP strategies }\end{array}$ & $\begin{array}{l}\text { All common } \\
\text { APP strategies }\end{array}$ \\
\hline $\begin{array}{c}\text { APP strategies } \\
\text { evaluation method }\end{array}$ & $\begin{array}{l}\text { Multiple } \\
\text { criteria }\end{array}$ & $\begin{array}{l}\text { Multiple } \\
\text { criteria }\end{array}$ & $\begin{array}{l}\text { Single } \\
\text { criterion }\end{array}$ & $\begin{array}{l}\text { Single } \\
\text { criterion }\end{array}$ & $\begin{array}{l}\text { Multiple } \\
\text { criteria }\end{array}$ & $\begin{array}{l}\text { Multiple } \\
\text { criteria }\end{array}$ & $\begin{array}{l}\text { Multiple } \\
\text { criteria }\end{array}$ & $\begin{array}{l}\text { Single } \\
\text { criterion }\end{array}$ & $\begin{array}{l}\text { Multiple } \\
\text { criteria }\end{array}$ \\
\hline $\begin{array}{c}\text { The most } \\
\text { preferred APP } \\
\text { strategy/method }\end{array}$ & $\begin{array}{l}\text { Chase } \\
\text { strategy }\end{array}$ & $\begin{array}{c}\text { Not } \\
\text { specified }\end{array}$ & $\begin{array}{l}\text { Search } \\
\text { decision } \\
\text { rule (SDR) }\end{array}$ & $\begin{array}{l}\text { Chase } \\
\text { strategy }\end{array}$ & $\begin{array}{l}\text { Chase } \\
\text { strategy }\end{array}$ & Level strategy & $\begin{array}{c}\text { Not } \\
\text { generally } \\
\text { specified }\end{array}$ & Chase strategy & Chase strategy \\
\hline $\begin{array}{c}\text { Demand } \\
\text { management } \\
\text { policy }\end{array}$ & Considered & $\begin{array}{c}\text { Not } \\
\text { considered }\end{array}$ & $\begin{array}{c}\text { Not } \\
\text { considered }\end{array}$ & $\begin{array}{c}\text { Not } \\
\text { considered }\end{array}$ & $\begin{array}{c}\text { Not } \\
\text { considered }\end{array}$ & $\begin{array}{c}\text { Not } \\
\text { considered }\end{array}$ & $\begin{array}{c}\text { Not } \\
\text { considered }\end{array}$ & Considered & Considered \\
\hline Pricing option & $\begin{array}{c}\text { Not } \\
\text { considered }\end{array}$ & $\begin{array}{c}\text { Not } \\
\text { considered }\end{array}$ & $\begin{array}{c}\text { Not } \\
\text { considered }\end{array}$ & $\begin{array}{c}\text { Not } \\
\text { considered }\end{array}$ & $\begin{array}{c}\text { Not } \\
\text { considered }\end{array}$ & $\begin{array}{c}\text { Not } \\
\text { considered }\end{array}$ & $\begin{array}{c}\text { Not } \\
\text { considered }\end{array}$ & Considered & Considered \\
\hline Advertising option & $\begin{array}{c}\text { Not } \\
\text { considered }\end{array}$ & $\begin{array}{c}\text { Not } \\
\text { considered }\end{array}$ & $\begin{array}{c}\text { Not } \\
\text { considered }\end{array}$ & $\begin{array}{c}\text { Not } \\
\text { considered }\end{array}$ & $\begin{array}{c}\text { Not } \\
\text { considered }\end{array}$ & $\begin{array}{c}\text { Not } \\
\text { considered }\end{array}$ & $\begin{array}{c}\text { Not } \\
\text { considered }\end{array}$ & Considered & Considered \\
\hline $\begin{array}{l}\text { Productivity } \\
\text { measures }\end{array}$ & $\begin{array}{c}\text { Not } \\
\text { considered }\end{array}$ & $\begin{array}{c}\text { Not } \\
\text { considered }\end{array}$ & $\begin{array}{c}\text { Not } \\
\text { considered }\end{array}$ & $\begin{array}{c}\text { Not } \\
\text { considered }\end{array}$ & $\begin{array}{c}\text { Not } \\
\text { considered }\end{array}$ & Considered & $\begin{array}{c}\text { Not } \\
\text { considered }\end{array}$ & $\begin{array}{c}\text { Not } \\
\text { considered }\end{array}$ & Considered \\
\hline Customer services & $\begin{array}{c}\text { Not } \\
\text { considered }\end{array}$ & $\begin{array}{c}\text { Not } \\
\text { considered }\end{array}$ & $\begin{array}{c}\text { Not } \\
\text { considered }\end{array}$ & $\begin{array}{c}\text { Not } \\
\text { considered }\end{array}$ & Considered & $\begin{array}{c}\text { Not } \\
\text { considered }\end{array}$ & Considered & $\begin{array}{c}\text { Not } \\
\text { considered }\end{array}$ & Considered \\
\hline $\begin{array}{c}\text { Production } \\
\text { resources and } \\
\text { capacity utilisation }\end{array}$ & $\begin{array}{c}\text { Not } \\
\text { considered }\end{array}$ & $\begin{array}{c}\text { Not } \\
\text { considered }\end{array}$ & $\begin{array}{c}\text { Not } \\
\text { considered }\end{array}$ & $\begin{array}{c}\text { Not } \\
\text { considered }\end{array}$ & Considered & $\begin{array}{c}\text { Not } \\
\text { considered }\end{array}$ & $\begin{array}{c}\text { Not } \\
\text { considered }\end{array}$ & $\begin{array}{c}\text { Not } \\
\text { considered }\end{array}$ & Considered \\
\hline Capacity decisions & $\begin{array}{c}\text { Not } \\
\text { considered }\end{array}$ & $\begin{array}{c}\text { Not } \\
\text { considered }\end{array}$ & $\begin{array}{c}\text { Not } \\
\text { considered }\end{array}$ & $\begin{array}{c}\text { Not } \\
\text { considered }\end{array}$ & $\begin{array}{c}\text { Not } \\
\text { considered }\end{array}$ & $\begin{array}{c}\text { Not } \\
\text { considered }\end{array}$ & $\begin{array}{c}\text { Not } \\
\text { considered }\end{array}$ & $\begin{array}{c}\text { Not } \\
\text { considered }\end{array}$ & Considered \\
\hline Learning effect & $\begin{array}{c}\text { Not } \\
\text { considered }\end{array}$ & $\begin{array}{c}\text { Not } \\
\text { considered }\end{array}$ & $\begin{array}{c}\text { Not } \\
\text { considered }\end{array}$ & $\begin{array}{c}\text { Not } \\
\text { considered }\end{array}$ & $\begin{array}{c}\text { Not } \\
\text { considered }\end{array}$ & $\begin{array}{c}\text { Not } \\
\text { considered }\end{array}$ & $\begin{array}{c}\text { Not } \\
\text { considered }\end{array}$ & $\begin{array}{c}\text { Not } \\
\text { considered }\end{array}$ & Considered \\
\hline
\end{tabular}




\section{The mathematical modelling representation of APP strategies}

\subsection{The mixed chase and level strategy}

The stochastic, nonlinear, multi-objective optimisation model of APP which was developed for the fundamental mixed chase and level strategy in Jamalnia et al. (2017) is reconsidered in present study. The mathematical models for other APP strategies including the pure chase, the pure level, the modified chase and the modified level strategies are constructed on the basis of the fundamental model developed for the mixed chase and level strategy. The model is concisely represented in Appendix A. The input data has been presented in Section 1 of Part 1 in supplementary materials in Appendix B.

As it was mentioned in Subsection 1.3, the uncertain demand is the driving force in APP process. Product demand is considered in three levels, low, average and high, with corresponding probabilities. Random demand variable and other demand-dependent random variables make stochastic programming an efficient approach to handle the resulting uncertain APP model. First, we apply the multi-stage recourse approach as a major stochastic programming approach, where all random variables and constraints associated with different scenarios are put together under the same model, while the objective functions represent the optimisation of the expected values related to demand volume scenarios.

The assigned capacity level for each product in each time period is supposed to be first stage decision variable, that is, the decision variables that their values are determined before the uncertainty is revealed. Other decision variables such as production in regular time, production in overtime, subcontracting and backordering are second stage decision variables, i.e. the variables that their values are determined when the uncertainty is revealed.

The core model developed for the mixed chase and level strategy for the industrial case under study by applying the recourse approach has 504 variables, over 1050 constraints and 7 objective functions. Apart from the deficiencies of the recourse approach, which is not the aim of present study, this model has no feasible space mostly because of the presence of large number of highly inconsistent constraints representing different demand volume scenarios. On the whole, we have to solve 5 (number of considered APP strategies)*3 (number of scenarios) $=15$ equal size problems with above-described characteristics when all models for different APP strategies and different demand quantity scenarios are considered.

As such, we resort to the wait and see approach as another stochastic programming methodology. By using the wait and see method, which does not put all constraints related to different demand scenarios together and then calculate the expected values in the objective functions, we will have an 
independent problem for each scenario. Once the solutions for these problems have been obtained, the expected value for each objective function is calculated regarding different scenarios.

Therefore, employing the wait and see approach creates three equal size problems with 184 variables, 205 constraints and 7 objectives, where each problem represents one of the three demand volume scenarios, i.e. low, average and high.

The resulting nonlinear, multi-objective optimisation problems are non-smooth due to the presence of $\mathrm{max} / \mathrm{min}$ operators, and non-differentiable because of the existence of absolute value functions and rational functions in the model. They are nonconvex as well, which diminishes the existing algorithms and software capabilities to deal with them efficiently. However, the WWW-NIMBUS software has the capability to run these kinds of problems. This internet-based software was developed by Miettinen and Mäkelä (2006), and is based mainly on NIMBUS (Non-differentiable Interactive Multi-objective BUndle-based optimisation System) algorithm that its first version was proposed by Miettinen and Mäkelä (1995).

The NIMBUS algorithm employs a classification scheme for objective functions. Those classes are functions whose values should be decreased, functions whose values should be decreased down till some aspiration level, functions whose values are satisfactory at the moment, functions whose values are allowed to increase up till some upper bound, and functions whose values are allowed to change freely. At each iteration, in an interactive way, the decision maker is asked to classify the objective functions regarding the current solution, and the possible aspiration levels and upper bounds (Miettinen and Mäkelä, 1995; Miettinen and Mäkelä, 2006). Then, the decision maker determines the maximum number of different solutions to be generated between one and four. The decision maker can choose one or more of the new solutions or may want to see intermediate solutions between two existing solutions.

To ensure the globally optimum solutions, especially in large-scale models, the WWW-NIMBUS contains two variants of genetic algorithms with different constraint handling methods: one acts on the basis of adaptive penalties, and another one is the method of parameter free penalties.

The same solution process is applied for other APP strategies.

\subsection{The pure chase strategy}

At first sight, a chase plan looks the optimum policy. It positively impacts a wide category of costs, and thus improves the company's earnings, and reduces its financial risks. Instead of excessive reliance on distant forecasted sales, the management seeks to adjust production capacity in a flexible way on the basis of near future demand predictions. It also gives a firm the opportunity to recruit a wide range of necessary skills on temporary basis. 
In practice, a chase strategy could be realistic choice provided that the production fluctuations are effectively handled. The rationale behind the chase policy is very similar to that of just in time (JIT) production. Conditions which require dealing with valuable, bulky or hard to store, perishable and under the risk of obsolescence products makes the chase plan ideal.

To implement the pure chase strategy, the subcontracting, inventory stock, backorder and demand management strategy components including pricing ad advertising options are disregarded in the model developed for the mixed chase and level strategy. The company is going to follow the JIT philosophy, that is, it receives the orders, and then produces accordingly.

As already stated, all quantitative models for relevant APP strategies are derived from the model developed for the basic mixed chase and level strategy.

Objective functions (3) and (4) remain unchanged. In practice, ignoring the possibility of backordering, keeping inventory, subcontracting, and so on means assigning the value 0 to them. Thus, by plugging 0 into objective functions (5) and (6), their value will be 1 and 0 respectively. Objective functions (1), (2) and (7) are modified as follows:

I) Maximise total revenue

$\operatorname{Max} Z_{1}^{S}=\sum_{n=1}^{N} \sum_{t=1}^{T}\left(Q_{r n s}^{t}+Q_{e n s}^{t}\right) F P R_{n s}^{t}$

Note that since the pricing option has been disregarded, the price in this equation is a fixed price.

II) Minimise total production costs

$\operatorname{Min} Z_{2}^{s}$

$$
\begin{aligned}
& =\sum_{n=1}^{N} \sum_{t=1}^{T} C_{p n}^{t}\left(Q_{r n s}^{t}+Q_{e n s}^{t}\right) \\
& +\sum_{n=1}^{N} \sum_{t=1}^{T}\left(Q_{r n s}^{t-1} P T_{r n s}^{t}+F_{r n}\left(\left|Q_{r n s}^{t}-Q_{r n s}^{t-1}\right|+\varepsilon\right)^{b_{r}} \max \left(\left(Q_{r n s}^{t}-Q_{r n s}^{t-1}\right), 0\right)\right. \\
& \left.-\max \left(\left(Q_{r n s}^{t-1}-Q_{r n s}^{t}\right), 0\right) P T_{r n s}^{t-1}\right) C_{r w n}^{t} \\
& +\sum_{n=1}^{N} \sum_{t=1}^{T}\left(Q_{\text {ens }}^{t-1} P T_{\text {ens }}^{t}+F_{\text {en }}\left(\left|Q_{\text {ens }}^{t}-Q_{\text {ens }}^{t-1}\right|+\varepsilon\right)^{b_{e}} \max \left(\left(Q_{\text {ens }}^{t}-Q_{\text {ens }}^{t-1}\right), 0\right)\right. \\
& -\max \left(\left(Q_{\text {ens }}^{t-1}\right.\right. \\
& \left.\left.\left.-Q_{\text {ens }}^{t}\right), 0\right) P T_{\text {ens }}^{t-1}\right) C_{\text {ewn }}^{t}
\end{aligned}
$$


III) Maximise utilisation of production resources and capacity

$\operatorname{Min} Z_{7}^{S}=\sum_{n=1}^{N} \sum_{t=1}^{T}\left[\left(1-\frac{Q_{r n s}^{t}}{P C_{r n}^{t}}\right)+\left(1-\frac{Q_{e n s}^{t}}{P C_{e n}^{t}}\right)\right] / 2 N T$

The constraints (9)-(11) and (22)-(32) remain unchanged, and the constraints (12)-(18), (20)-(21) and (33) are removed from consideration. The upper bounds for constraints (30) and (31) are increased up to $50 \%$. The constraint (19) is transformed into the following constraint:

$Q_{r n s}^{t}+\left(\frac{\max \left(D_{n s}^{t}-P C_{r n}^{t}, 0\right)}{\max \left(D_{n s}^{t}-P C_{r n}^{t}, 0\right)+\varepsilon}\right) Q_{e n s}^{t}=D_{n s}^{t}$ $\forall n, \forall t, \forall s$

\subsection{The modified chase strategy}

The limited production resources available for companies make it hard or even impossible to chase the customer demand closely. Furthermore, regarding the lengthy training periods for the newly hired workforce, sharp and instant ramp up in workforce level would not be an easy task. These reasons urge the operations managers to choose a modified chase policy. The modified chase strategy necessitates keeping given quantity of inventories.

To apply the modified chase plan, stockpiling option is allowed in all time periods. In time periods 3 and 4, i.e. autumn and winter when the demand for soft drink products fall, the firm will store a previously determined volume of products, e.g. $10-15 \%$ of demand volume in order to be used in upcoming periods especially in time periods 1 and 2.

Hence, in the model developed for the pure chase strategy, the objective $Z_{6}$ is reconsidered but it only includes the inventory holding costs. Therefore, we must have:

I) Minimise total inventory holding costs

$\operatorname{Min} Z_{6}^{S}=\sum_{n=1}^{N} \sum_{t=1}^{T} C_{i n}^{t} I_{n S}^{t}$

And, the constraint (19) is modified as follows:

$I_{n s}^{t-1}+Q_{r n s}^{t}+\left(\frac{\max \left(D_{n s}^{t}-P C_{r n}^{t}-I_{n s}^{t-1}, 0\right)}{\max \left(D_{n s}^{t}-P C_{r n}^{t}-I_{n s}^{t-1}, 0\right)+\varepsilon}\right) Q_{e n s}^{t}-D_{n s}^{t}$

$=I_{n s}^{t}$

The constraint (33) is also added to the list of constraints.

According to the modified chase strategy, no subcontracting and backorder is allowed, inventory stocked in all time periods are procured by production level beyond the demand volume, pricing and 
demand management policies are not applied, and the demand is met fully. Therefore, the sales volume and thus revenue would remain the same as the pure chase strategy.

\subsection{The pure level strategy}

In spite of numerous advantages that already mentioned for the chase policy, there are conditions which limit its applicability, e.g. situations where the recruited workforce needs intensive and continuous training. Additionally, as already stated, the frequent hiring and firing would lead to productivity losses and the workers motivation decline.

To put the pure level strategy into practice, hiring and lay off in both regular shift and extra shift are ignored, and any variation in the customer demand must be met by applying all other available options such as inventory, overtime, subcontracting, backorder or any of the demand influencing policies.

The maximum 3 hour overtime besides the normal 8 hour regular shift is performed by the current workforce. The upper bound of the subcontracting is increased to $30 \%$ of the adjusted demand in each time period.

Ignoring hiring and lay-off options means their corresponding decision variables take on the value 0 , and therefore the objectives $Z_{3}$ and $Z_{4}$ also assume the value 0 . All other objective functions except objective function (2) remain unchanged.

The new objective function (2) will be as follows:

I) Total production costs

$\operatorname{Min} Z_{2}^{S}$

$=\sum_{n=1}^{N} \sum_{t=1}^{T} C_{p n}^{t}\left(Q_{r n s}^{t}+Q_{e n s}^{t}\right)+\sum_{n=1}^{N} \sum_{t=1}^{T} C_{r w n}^{t}\left(Q_{r n s}^{t} P T_{n}\right)+C_{e w n}^{t}\left(Q_{e n s}^{t} P T_{n}\right)$

$+\sum_{n=1}^{N} \sum_{t=1}^{T} C_{s n}^{t} S_{n s}^{t}$

Where $P T_{n}$ represents the normal production time, when there is no hiring and lay off, regardless of demand scenarios and operating in regular shift or overtime. $Q_{e n s}^{t}$ shows production quantity in overtime.

Constraints (9)-(21), (32) and (33) remain unchanged. Constraints (22)-(29) are lifted.

Constraints (30) and (31), workforce level constraints, are transformed into a single constraint as below: 
$\sum_{n=1}^{N}\left(Q_{r n s}^{t}+Q_{e n s}^{t}\right) P T_{n} \leq W_{s \max }^{t}$

Because the existing workforce carries out the overtime as well, the upper limit of the labour force, $W_{s}^{t}$ max , has no notation of operating in regular shift or overtime but the maximum 3 hour overtime is added to the 8 hour regular shift working hours to calculate this upper bound.

\subsection{The modified level strategy}

Normally, there are limits on storage capacity available. In addition, increase in accumulated backlogged orders would have serious impact on customer satisfaction level. Moreover, skilled workforce may need several months to master certain tasks, and several years to achieve complete job rotation. This means regular hiring and lay off when dealing with the skilled workers would be waste of time and money. These are instances which call for the modified level strategy.

To execute this strategy, the company keeps its core skilled workers, and performs hiring and firing for the lower skilled workforce. The subcontracting upper limit is lowered to $25 \%$ of the adjusted demand. Hiring and laying off costs are reduced 35\%, and workers learning rate is increased to 0.975 , because of dealing with lower skilled manpower. Hiring and lay off will have an upper bound which is supposed to be $40 \%$ of the hiring and lay off in the mixed chase and level strategy. All other objectives and constraints do not change.

\subsection{Initial comparison of APP strategies performance using mathematical modelling}

The solutions for objectives with regard to each APP strategy are presented in Table 2. Please remember that all monetary values, e.g. costs, revenues, profits, etc. are in British Pound (GBP). To calculate the total profit column in Table 2 , the cost items, $Z_{2}, Z_{3}, Z_{4}$ and $Z_{6}$, are deducted from the total revenue, $Z_{1}$, for each demand scenario.

The mixed chase and level strategy: Because the quantity of backorder in comparison with the demand volume is relatively low for all products, the customer satisfaction level, $Z_{5}$, is consequently quite high for all scenarios. Since most of the received orders are met by manufacturing in regular shift and extra shift instead of subcontracting, the unutilised production capacity and resources, $Z_{7}$, is significantly low, i.e. lower than $10 \%$ in all scenarios. The highest and lowest amounts among the cost items belongs to total production costs and total labour productivity costs respectively. The row $E\left(Z_{k}\right)$ is the expected value of each column.

The pure chase strategy: As can be seen from Table 2, total expected revenue and total expected production costs, $E\left(Z_{1}\right)$ and $E\left(Z_{2}\right)$ respectively, are lower than that of mixed chase and level strategy because the demand management policy embedded in the mixed chase and level strategy 
causes an increase in adjusted demand quantity, and therefore increase in the sales quantity and total production costs accordingly. But, the lesser decrease in total expected revenue, $2.57 \%$, compared to the expected proportionate decrease which is seen in total expected production costs, $14.30 \%$, is due to the lowered prices in the mixed chase and level strategy case that are lower than the fixed prices, $F P R_{n s}^{t}$, as result of applying the pricing policy. A part of the decrease in total production costs would also be attributed to the lower costs of producing in regular shift and extra shift compared to subcontracting costs which has been discarded in current operations strategy. As is expected, the pure chase strategy has resulted in higher costs of changes in labour force level and costs related to human resource productivity and their corresponding expected values, i.e. $E\left(Z_{3}\right)$ and $E\left(Z_{4}\right)$. However, the amount of this rise might not be as much as expected because the demand adjustment mechanism applied with the mixed chase and level strategy would have a contribution in unsmoothing the demand level which in turn will cause higher rates of hiring and lay off.

The pure chase strategy tries to meet the market demand solely by producing in regular shift and extra shift, and adjusting the manufacturing capacity by varying the workforce level. Therefore, it has much better performance in utilising the company's production capacity and resources, which is approved by very small percentage of unutilised production resources/capacities in $E\left(Z_{7}\right)$.

The pure chase plan presents a significantly higher expected profit in comparison with the basic mixed chase and level strategy.

Although, the mixed chase and level strategy contributes to revenue/sales growth but as stated above, at the same time the price reductions due to the lower volumes of the backorders neutralise a portion of sales growth impact on total revenue. On the other side, the increase in demand causes a corresponding increase in production, and thus total production costs. In addition to these factors, ignoring the $Z_{6}$, total inventory carrying, backordering and advertising costs, explains the higher total profit for the pure chase strategy despite the slight increases in $Z_{3}$ and $Z_{4}$.

The modified chase strategy: Since the inventory keeping plan, especially in time periods 3 and 4 , mandates higher production amounts in these time periods in comparison with the same time periods in the pure chase strategy case, the total production quantity and consequently the total production costs show the proportionate increase.

Although, when the modified chase plan is used, lower $Z_{3}$ and $Z_{4}$, total costs of changes in workforce level and total labour productivity costs, are generally expected but because this strategy is applied for the first time over the planning horizon, and very limited amount of inventory is available at the beginning of the planning horizon to be used particularly in time periods 1 and 2, the company has to hire higher levels of labour force in time periods 1 and 2 (to meet the risen demand 
and stock some inventory), and then lay off higher levels of workforce in time periods 3 and 4 due to significant decline in the market demand in autumn and winter (Even though, keeping a minimum volume of inventory is still considered but the sharp decrease in demand compensates the effect of increase in production for inventory stocking purpose).

Compared to the pure chase strategy, $Z_{7}$, the optimum utilisation of the production capacity and company's resources, shows a very slight improvement normally as result of higher levels of production in both regular shift and extra shift which would mean better utilisation of the company's manufacturing capacity.

However, the total expected profit declines slightly, i.e. 3.824\%.

The pure level strategy: In comparison with the mixed chase and level plan, total expected revenue, $E\left(Z_{1}\right)$, has declined about $23.044 \%$ mainly for two reasons: I) the backorder quantities for all products in all time periods go beyond the threshold level, and in two occasions of the three occasions, i.e. when the product demand turns out to be low and average, the demand adjustment mechanism, which would have led to an increase in demand, is turned off. Moreover, in case that high demand scenario occurs, again because backorder volume has exceeded the threshold level, the demand management policy causes a proportionate decrease in the demand. Consequently, the demand volume and therefore the sales amount is reduced, II) the higher level of backorder means a portion of the demand is unsatisfied within the planning horizon which correspondingly has a negative impact on total revenue.

The production decline as result of abovementioned reasons explains the proportional decrease in total production costs, $Z_{2}$, as well.

As is expected, the rampant increase in backorder and subcontracting volumes would lead to a significant drop in customer satisfaction, $Z_{5}$, and sharp rises in total inventory holding, backordering and advertising costs, $Z_{6}$, and unutilised production resources and capacity, $Z_{7}$. The huge increase in $Z_{6}$ has the highest contribution in turning the total profit into a considerable loss.

The modified level strategy: Even though similar to the pure level strategy case, the backorder volume still surpasses the threshold level in all time periods for all products and for all demand scenarios but partial hiring and lay off helps reduce the overwhelmingly high quantity of backorders through higher production rates, that in turn helps increase the satisfied demand volume, and then the sales amount, $Z_{1}$. Compared to the pure level strategy, the higher production rates in regular shift and extra shift leads to higher total production costs, $Z_{2}$. As previously stated, the objective function $Z_{3}$ is to minimise the positive deviations from standard production time. The learning effect contributes to a significant improvement in production time of all products by newly hired workforce after producing a significant volume of products so that they even fall below the standard 
production time of those products. Moreover, the restricted lay off levels (alongside the restricted hiring levels) have had a similar effect to that of learning effect through hiring, and have caused the production time of different products become shorter than their standard production times. Thus, total positive deviations from the standard production times, $Z_{3}$, turns out to be almost zero.

The reduced costs of hiring and firing together with constrained hiring and firing levels result in decreased $Z_{4}$ or total costs of changes in workforce level. $Z_{5}$, customer satisfaction, improves as result of reduction in huge quantity of the backlogged orders. Decrease in backorder volumes directly causes a fall in total inventory, backorder and advertising costs, $Z_{6}$. As is expected, diminish in backorder volumes and growth in production rates lead to more effective use of manufacturing capacity and production resources, which is reflected in $Z_{7}$.

Finally, the tangible improvement in cash flow, through sales rise and a significant decrease in $Z_{6}$, makes the total profit positive.

Table 2: The solutions for objectives with regard to each APP strategy

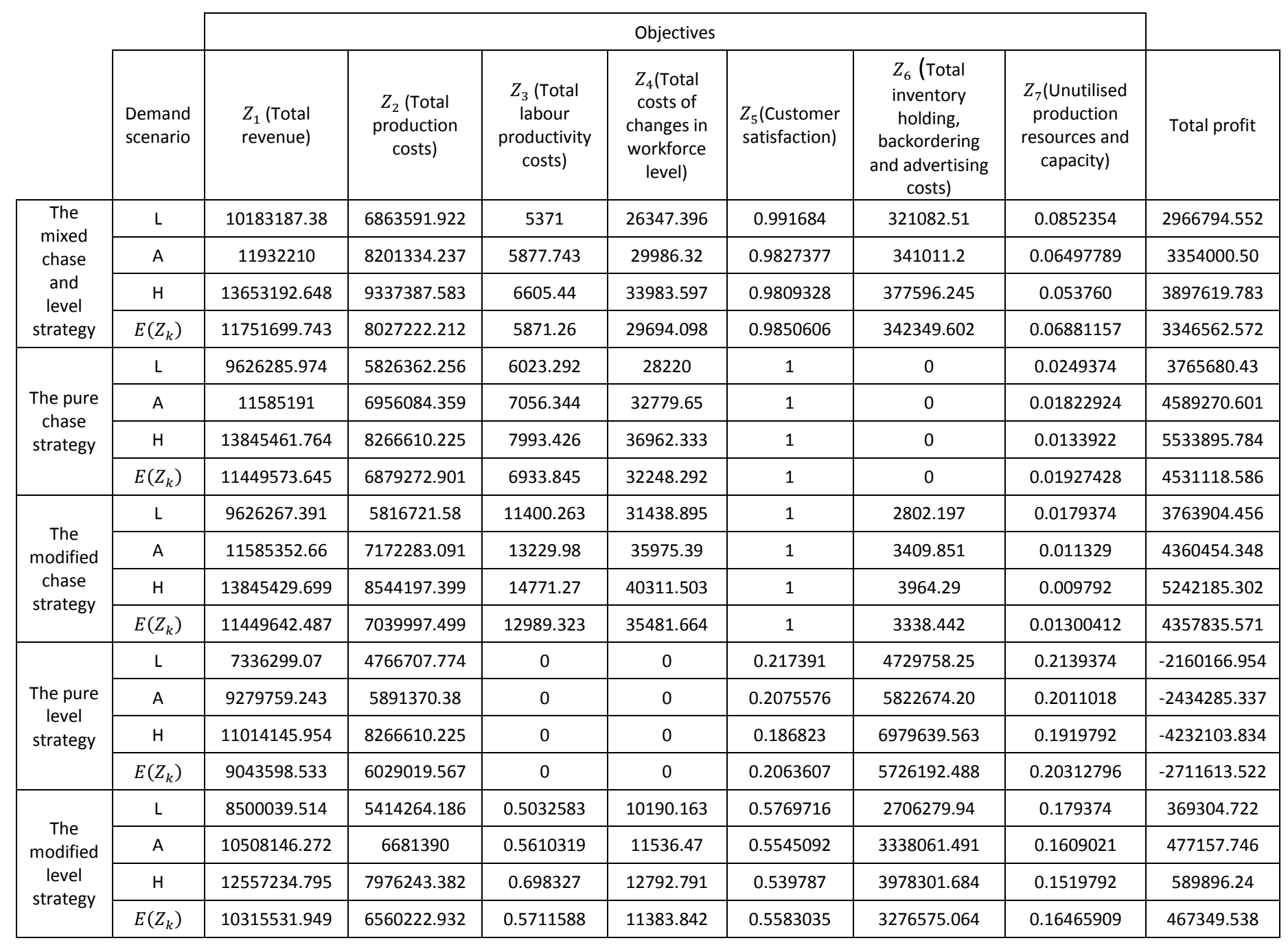




\section{Further analysis of the results}

\subsection{Assessing the performance of APP strategies based on single criterion}

The aforementioned APP strategies are ranked based on each of the eight criteria mentioned above which has been presented in Table 3 .

Table 3: APP strategy rankings based on single criterion.

\begin{tabular}{|c|c|c|c|c|c|c|c|c|}
\cline { 2 - 10 } \multicolumn{1}{l|}{} & \multicolumn{9}{c|}{ Criteria } & \multicolumn{1}{c|}{ APP strategy } & $E\left(Z_{1}\right)$ & $E\left(Z_{2}\right)$ & $E\left(Z_{3}\right)$ & $E\left(Z_{4}\right)$ & $E\left(Z_{5}\right)$ & $E\left(Z_{6}\right)$ & $E\left(Z_{7}\right)$ & $\begin{array}{c}\text { Total expected } \\
\text { profit (GBP) }\end{array}$ \\
\hline The mixed chase and level & 1 & 5 & 3 & 3 & 3 & 3 & 3 & 3 \\
\hline The pure chase & 2 & 3 & 4 & 4 & 1 & 1 & 2 & 1 \\
\hline The modified chase & 3 & 4 & 5 & 5 & 1 & 2 & 1 & 2 \\
\hline The pure level & 5 & 1 & 1 & 1 & 5 & 5 & 5 & 5 \\
\hline The modified level & 4 & 2 & 2 & 2 & 4 & 4 & 4 & 4 \\
\hline
\end{tabular}

\subsection{Assessing the performance of APP strategies using MCDM methods}

The MCDM techniques, AVF, TOPSIS and VIKOR, are used to assess the overall performance of different APP strategies by taking all of the criteria mentioned above into account except total profit, again to avoid the significant overlaps between criteria.

First, the criteria are assigned weights by employing the analytic hierarchy process (AHP), and then these weights are utilised in the process of aggregation used by the aforementioned methods. The weights of the criteria $Z_{1}-Z_{7}$ are respectively determined as: $0.3203,0.2219,0.0624,0.0781,0.1339$, 0.1379 and 0.0453 . Table 4 shows the overall rankings of the APP strategies together with total aggregated scores regarding each strategy.

As Table 4 indicates, the APP strategies from the chase family dominate in rankings performed by AVF and VIKOR but the level strategies top the list of TOPSIS ranking. In AVF ranking, the pure level strategy stays just behind chase strategies, and outperforms both mixed chase and level and modified level strategies with slightly higher overall score. In the ranking conducted by the VIKOR method, the modified level strategy stays next to the mixed chase and level strategy, and the pure level strategy is at the bottom of the list.

The TOPSIS ranking puts the pure chase plan in third place, which is followed by the mixed chase and level and the modified chase strategies respectively with very close scores. 
Table 4: APP strategy rankings

\begin{tabular}{|c|c|c|c|c|c|c|c|c|}
\hline \multicolumn{3}{|c|}{ AVF } & \multicolumn{3}{|c|}{ TOPSIS } & \multicolumn{3}{|c|}{ VIKOR } \\
\hline APP strategy & $\begin{array}{l}\text { Overall } \\
\text { score }\end{array}$ & Rank & APP strategy & $\begin{array}{l}\text { Overall } \\
\text { score }\end{array}$ & Rank & APP strategy & $\begin{array}{l}\text { Overall } \\
\text { score }\end{array}$ & Rank \\
\hline The pure chase & 0.80891 & 1 & The pure level & 0.61257 & 1 & The pure chase & 0 & 1 \\
\hline The modified chase & 0.68131 & 2 & The modified level & 0.61072 & 2 & The modified chase & 0.10506 & 1 \\
\hline The pure level & 0.64702 & 3 & The pure chase & 0.54655 & 3 & The modified level & 0.43269 & 2 \\
\hline $\begin{array}{c}\text { The mixed chase } \\
\text { and level }\end{array}$ & 0.62743 & 4 & $\begin{array}{c}\text { The mixed chase } \\
\text { and level }\end{array}$ & 0.38815 & 4 & $\begin{array}{c}\text { The mixed chase } \\
\text { and level }\end{array}$ & 0.41144 & 2 \\
\hline The modified level & 0.56342 & 5 & The modified chase & 0.38743 & 5 & The pure level & 1.0 & 5 \\
\hline
\end{tabular}

The results of these three rankings are now aggregated by calculating the rank averages and by Borda and Copeland methods which are presented in Table 5.

According to Table 5, the chase strategies top the list when the rankings are aggregated through computing the average of the ranks and Borda and Copeland methods, followed by the level strategies and the mixed chase and level strategy. The ranking results of the both Borda and Copeland methods are exactly the same.

Table 5: The aggregation of APP strategy rankings

\begin{tabular}{|c|c|c|c|c|c|c|c|}
\hline & \multicolumn{3}{|c|}{ Ranking method } & \multirow[b]{2}{*}{$\begin{array}{l}\text { Ranks } \\
\text { average }\end{array}$} & \multirow[b]{2}{*}{$\begin{array}{l}\text { Rank order } \\
\text { according to ranks } \\
\text { average }\end{array}$} & \multirow[b]{2}{*}{$\begin{array}{l}\text { Rank order } \\
\text { according to } \\
\text { Borda method }\end{array}$} & \multirow[b]{2}{*}{$\begin{array}{c}\text { Rank order } \\
\text { according to } \\
\text { Copeland } \\
\text { method }\end{array}$} \\
\hline APP strategy & AVF & TOPSIS & VIKOR & & & & \\
\hline $\begin{array}{l}\text { The mixed chase } \\
\text { and level }\end{array}$ & 4 & 4 & 2 & 3.33 & 5 & 4 & 4 \\
\hline The pure chase & 1 & 3 & 1 & 1.66 & 1 & 1 & 1 \\
\hline The modified chase & 2 & 5 & 1 & 2.66 & 2 & 2 & 2 \\
\hline The pure level & 3 & 1 & 5 & 3 & 3 & 3 & 3 \\
\hline The modified level & 5 & 2 & 2 & 3 & 3 & 4 & 4 \\
\hline
\end{tabular}

Considering all the above, insightful remarks from both academic and business viewpoints are provided as follows:

I. In current study, in the mixed chase and level strategy condition, in all time periods, regarding all demand scenarios, the backorder volumes fell below the threshold levels according to the real world data gathered from the company under study. If the backorder quantities had exceeded the threshold levels, the results would have probably been different considering the degree to which the backorders have surpassed the threshold points. 
II. With regard to the extent to which a production process is capital-intensive or labourintensive, it might be questionable that to what degree increasing the workforce level by recruiting the workers would necessarily mean a corresponding increase in production rate. However, ZamZam Company has already been operating with significant idle production capacity as it lost a portion of its market share to the newly established Pepsi and Coca Cola companies' branches throughout the country in recent years. This implies that regular hiring could effectively help increase the production volume in the corporation under study.

III. A moderate rate of hiring and lay off and wage costs were considered in present research. However, higher rates of these cost items besides the higher weights for $Z_{3}$ and $Z_{4}$, total labour productivity costs and total costs of changes in workforce level, might have considerable effect on APP strategy ranks.

\subsection{Sensitivity analysis of the rankings}

In this part, the sensitivity of the ranking results to changes in the weights assigned to each criterion is examined, and the outcomes are presented in Table 6 . The sensitivity analysis is conducted by changing the present weights of the criteria, $\left(W_{1}, W_{2}, W_{3}, W_{4}, W_{5}, W_{6}, W_{7}\right)=(0.3203,0.2219$, $0.0624,0.0781,0.1339,0.1379,0.0453)$, as follows:

Scenario 1: Put new weights $=(0.3803,0.1819,0.0824,0.0981,0.1239,0.0879,0.0453)$.

Scenario 2: Put new weights $=(0.3503,0.1019,0.0624,0.0781,0.1339,0.2579,0.0153)$.

Scenario 3: Put new weights $=(0.3203,0.0419,0.1624,0.1781,0.0339,0.0379,0.2253)$.

Scenario 4: Put new weights $=(0.0703,0.0519,0.1724,0.2281,0.3039,0.0979,0.0753)$.

Note that the abovementioned weight changes could lead to different rankings with regard to specific procedures that are used by each ranking technique. This justifies the significant difference between the ranking obtained by VIKOR and two other methods in spite of similar changes in criteria weights, e.g. unlike AVF and TOPSIS rankings, in VIKOR ranking the mixed chase and level and the pure chase strategies are ranked number one.

Again, the rankings of different methods are aggregated by average of the ranks and Borda and Copeland methods to have a more unified ranking of APP strategies, which are also shown in Table 6. 
Table 6: The sensitivity analysis results

\begin{tabular}{|c|c|c|c|c|c|c|c|c|c|c|}
\hline & \multirow{2}{*}{\multicolumn{6}{|c|}{ Ranking method }} & \multirow{3}{*}{\multicolumn{3}{|c|}{$\begin{array}{l}\text { Final } \\
\text { Rank }\end{array}$}} \\
\hline & & & & & & & & & & \\
\hline & & \multicolumn{2}{|c|}{ AVF } & \multicolumn{2}{|c|}{ TOPSIS } & \multicolumn{2}{|c|}{ VIKOR } & & & \\
\hline New weights & APP strategy & $\begin{array}{l}\text { Overall } \\
\text { score }\end{array}$ & Rank & $\begin{array}{l}\text { Overall } \\
\text { score }\end{array}$ & Rank & $\begin{array}{l}\text { Overall } \\
\text { score }\end{array}$ & Rank & $\begin{array}{c}\text { Ranks } \\
\text { average }\end{array}$ & $\begin{array}{l}\text { Borda } \\
\text { method }\end{array}$ & $\begin{array}{l}\text { Copeland } \\
\text { method }\end{array}$ \\
\hline \multirow{5}{*}{$\begin{array}{c}\text { Scenario 1: } \\
(0.3803,0.1819,0.0824 \\
0.0981,0.1239 \\
0.0879,0.0453)\end{array}$} & The mixed chase and level & 0.64753 & 4 & 0.39470 & 4 & 0.24785 & 3 & 4 & 4 & 4 \\
\hline & The pure chase & 0.77230 & 1 & 0.42941 & 3 & 0 & 1 & 1 & 1 & 1 \\
\hline & The modified chase & 0.69550 & 2 & 0.38743 & 5 & 0.09439 & 1 & 2 & 2 & 2 \\
\hline & The pure level & 0.69062 & 3 & 0.61257 & 1 & 1 & 5 & 3 & 3 & 3 \\
\hline & The modified level & 0.57375 & 5 & 0.59429 & 2 & 0.43845 & 4 & 4 & 5 & 5 \\
\hline \multirow{5}{*}{$\begin{array}{c}\text { Scenario } 2: \\
(0.3503,0.1019,0.0624 \\
0.0781,0.1339 \\
0.2579,0.0153)\end{array}$} & The mixed chase and level & 0.56163 & 3 & 0.58071 & 2 & 0.08240 & 1 & 2 & 2 & 3 \\
\hline & The pure chase & 0.83272 & 1 & 0.61257 & 1 & 0 & 1 & 1 & 1 & 1 \\
\hline & The modified chase & 0.57776 & 2 & 0.53225 & 3 & 0.05136 & 1 & 2 & 2 & 2 \\
\hline & The pure level & 0.54825 & 4 & 0.38743 & 5 & 1 & 5 & 5 & 5 & 5 \\
\hline & The modified level & 0.47710 & 5 & 0.52835 & 4 & 0.46048 & 4 & 4 & 4 & 4 \\
\hline \multirow{5}{*}{$\begin{array}{c}\text { Scenario 3: } \\
(0.3203,0.0419,0.1624 \\
0.1781,0.0339 \\
0.0379,0.2253)\end{array}$} & The mixed chase and level & 0.42774 & 4 & 0.44384 & 4 & 0.03880 & 1 & 4 & 3 & 4 \\
\hline & The pure chase & 0.57259 & 3 & 0.56661 & 3 & 0.03743 & 1 & 1 & 2 & 2 \\
\hline & The modified chase & 0.60715 & 2 & 0.38743 & 5 & 0.22757 & 1 & 3 & 3 & 3 \\
\hline & The pure level & 0.65224 & 1 & 0.61257 & 1 & 1 & 5 & 1 & 1 & 1 \\
\hline & The modified level & 0.35638 & 5 & 0.60727 & 2 & 0.33369 & 4 & 5 & 5 & 5 \\
\hline \multirow{5}{*}{$\begin{array}{c}\text { Scenario } 4: \\
(0.0703,0.0519,0.1724, \\
0.2281,0.3039 \\
0.0979,0.0753)\end{array}$} & The mixed chase and level & 0.42287 & 4 & 0.41950 & 3 & 0.08893 & 1 & 3 & 2 & 2 \\
\hline & The pure chase & 0.56658 & 2 & 0.41890 & 4 & 0.10291 & 1 & 1 & 2 & 2 \\
\hline & The modified chase & 0.49214 & 3 & 0.38743 & 5 & 0.42696 & 4 & 5 & 5 & 5 \\
\hline & The pure level & 0.59143 & 1 & 0.61257 & 1 & 1 & 5 & 1 & 1 & 1 \\
\hline & The modified level & 0.28502 & 5 & 0.59983 & 2 & 0.21072 & 1 & 3 & 2 & 2 \\
\hline
\end{tabular}

\subsection{Simulation modelling of APP strategies}

In our previous study, Jamalnia and Feili (2013), we applied an integrated discrete event simulation (DES) and system dynamics (SD) methodology (abbreviated as DES-SD) to assess the performance of APP strategies with regard to total profit criterion. This study also applies DES-SD simulation models which include the eight criteria and the new features of the mathematical models presented in Section 3. DES limits the scope of simulation to detailed analysis at an operational level while SD is more suitable for decision making at the aggregate and strategic levels (Baines and Harrison, 1999). Considering the aggregate nature of APP and its strategic focus, SD would be a useful technique to model and analyse its performance. Therefore, the operational level and shop-floor activities in APP are simulated by DES while SD is used to simulate APP as a medium term planning with strategic focus. The output of DES model is estimated values of time constants used in SD model such as Time to Subcontract, Time to Hire in Regular Time and Time Lay Off in Regular Time. The equations of the fundamental SD model for the mixed chase and level strategy are presented in detail in Part 2 in supplementary materials in Appendix B. 
To avoid excessive elaboration, the most probable scenario, the average demand scenario, $A$, is simulated. Similar to the mathematical models of APP strategies, the simulation models for other APP strategies are derived from the core simulation model for the mixed chase and level strategy which has been presented in Figure 2. Vensim PLE 7.2 was used for SD simulation of APP strategies. Figure $3 \mathrm{a}$ and Figure $3 \mathrm{~b}$ depict the DES models for the manufacturing and workforce employment processes respectively in the company under study by using the simulation software Arena 14.0.

Time steps in the simulation are supposed to be one month. Hence, the planning horizon is divided into 12 time periods, and the received orders and dependent variables are averaged over a three month period, i.e. a season to better reflect the seasonal nature of the market demand. All APP strategies are simulated with regard to the conditions described in Section 3, except that when executing the modified chase strategy, the stockpiled inventory is procured by subcontracting.

Figure $4 \mathrm{a}$ to Figure $4 \mathrm{~h}$ and Table 7 show comparison of different APP strategies regarding eight different criteria using SD simulation. The numerical results of SD simulation for eight different criteria regarding different APP strategies over a 12 month period (the planning horizon), which corresponds to Figure 4a-Figure 4h, is presented in Table 4a-Table $4 \mathrm{~h}$ in Section 2 of Part 1 in supplementary materials Appendix B.

Although simulation results confirm most of the results obtained by mathematical modelling, but the slight differences in values for different criteria in simulation modelling compared to those of mathematical modelling are attributed to the fundamental differences between simulation modelling and mathematical modelling. For example, presence of time constants, delays and stock and flow variables in simulation modelling can lead to different numerical solutions in comparison with mathematical modelling. However, comparing different APP strategies' performance on the basis of each criterion within simulation modelling and between simulation modelling and mathematical modelling is still insightful. 


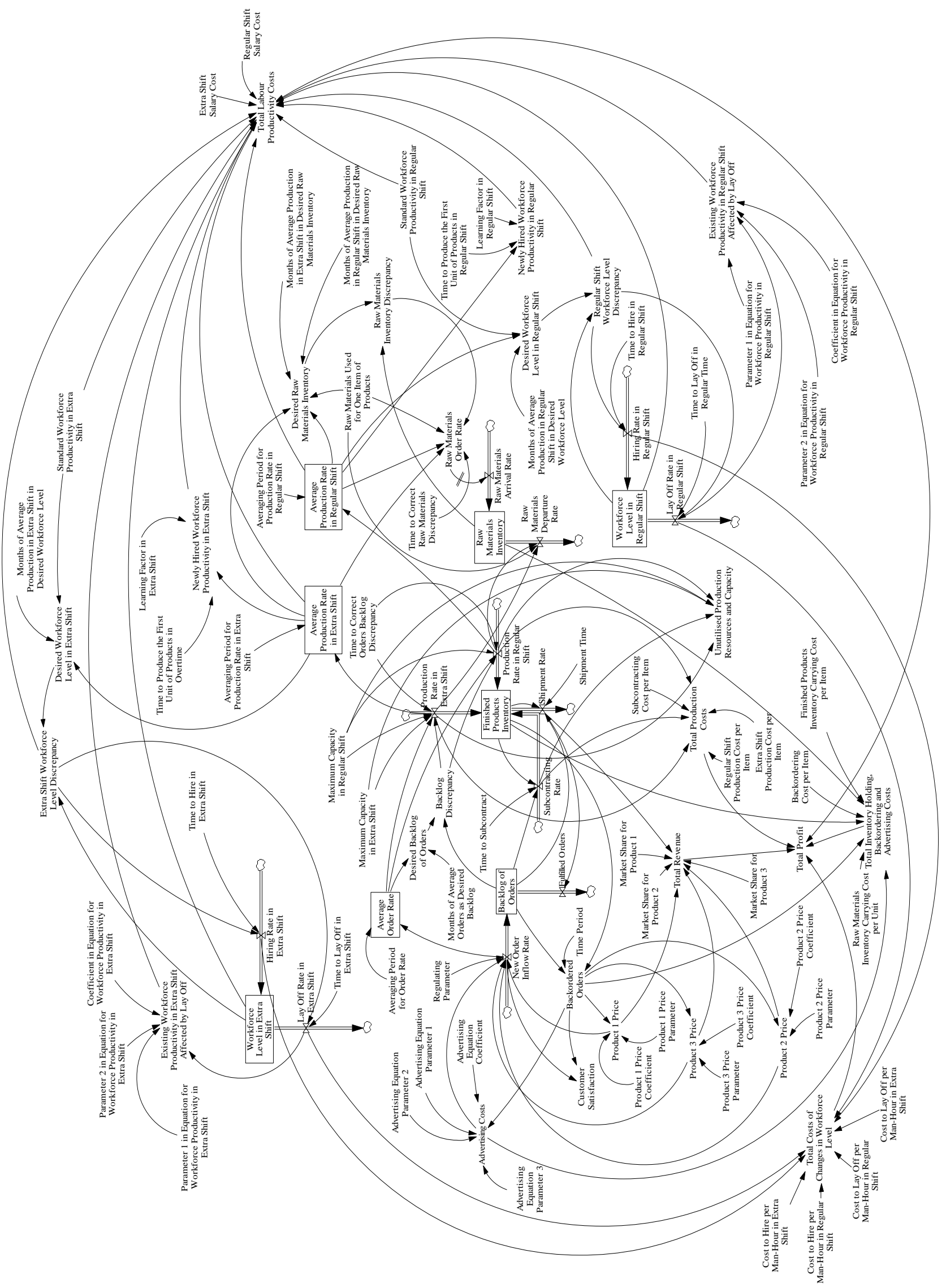

Figure 2: Stock and flow diagram for APP under the mixed chase and level strategy 


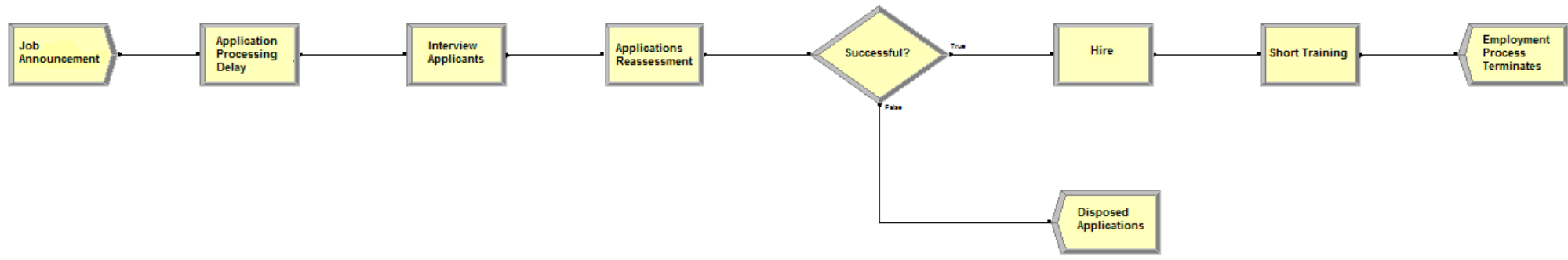

Figure 3a: DES simulation of employment process of the company under study

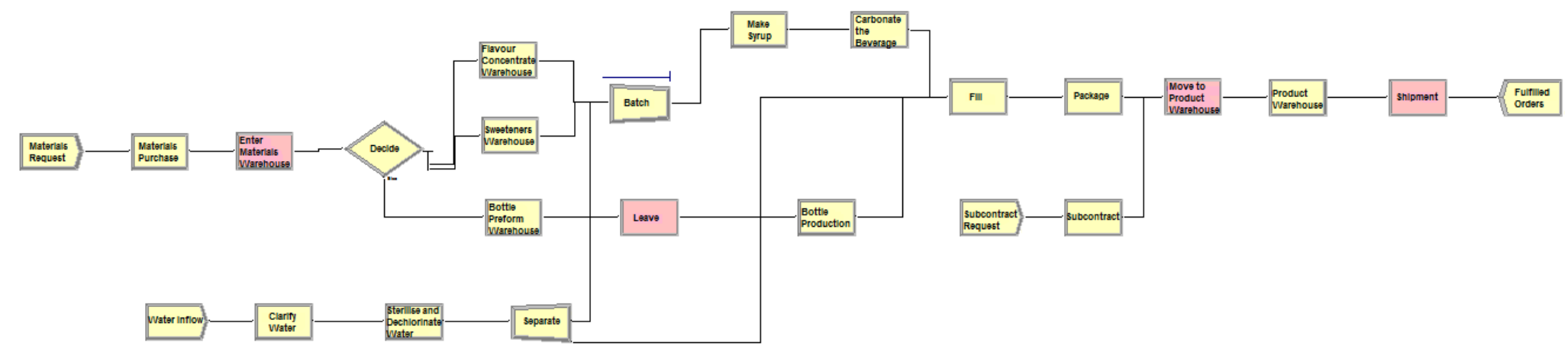

Figure 3b: DES simulation of manufacturing process of the company under study

As can be seen from Figure 4a and Table 7, the modified chase strategy with the cumulative total profit of 5276911 for 12 months comes in first place when total profit measure is considered. The pure chase and the mixed chase and level strategies come in second and third places respectively. Although in the mathematical model, the pure chase strategy has the highest total profit, it generally approves the simulation modelling rankings as chase strategies still top the list, and the order of other APP strategies remain unchanged.

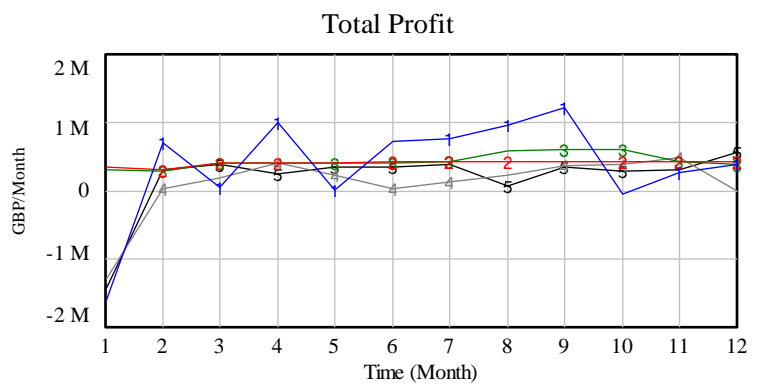

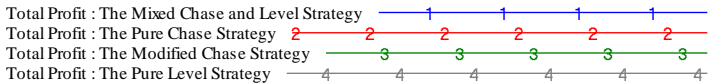
Total Profit : The Modified Level Strategy

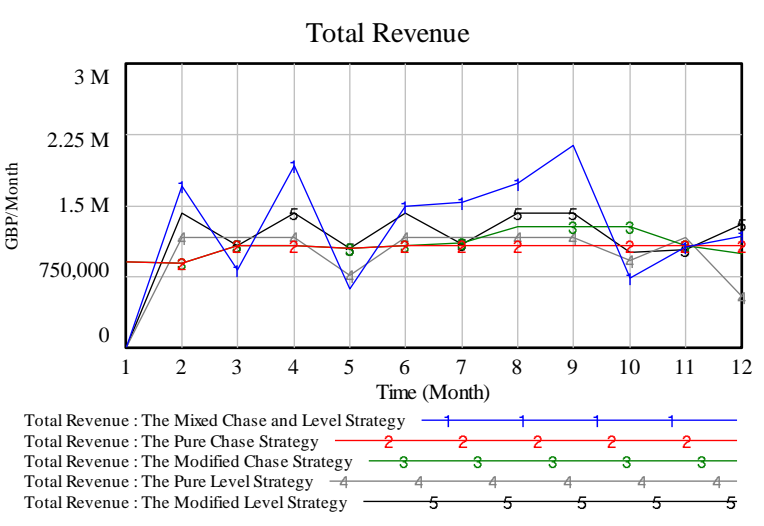

b 

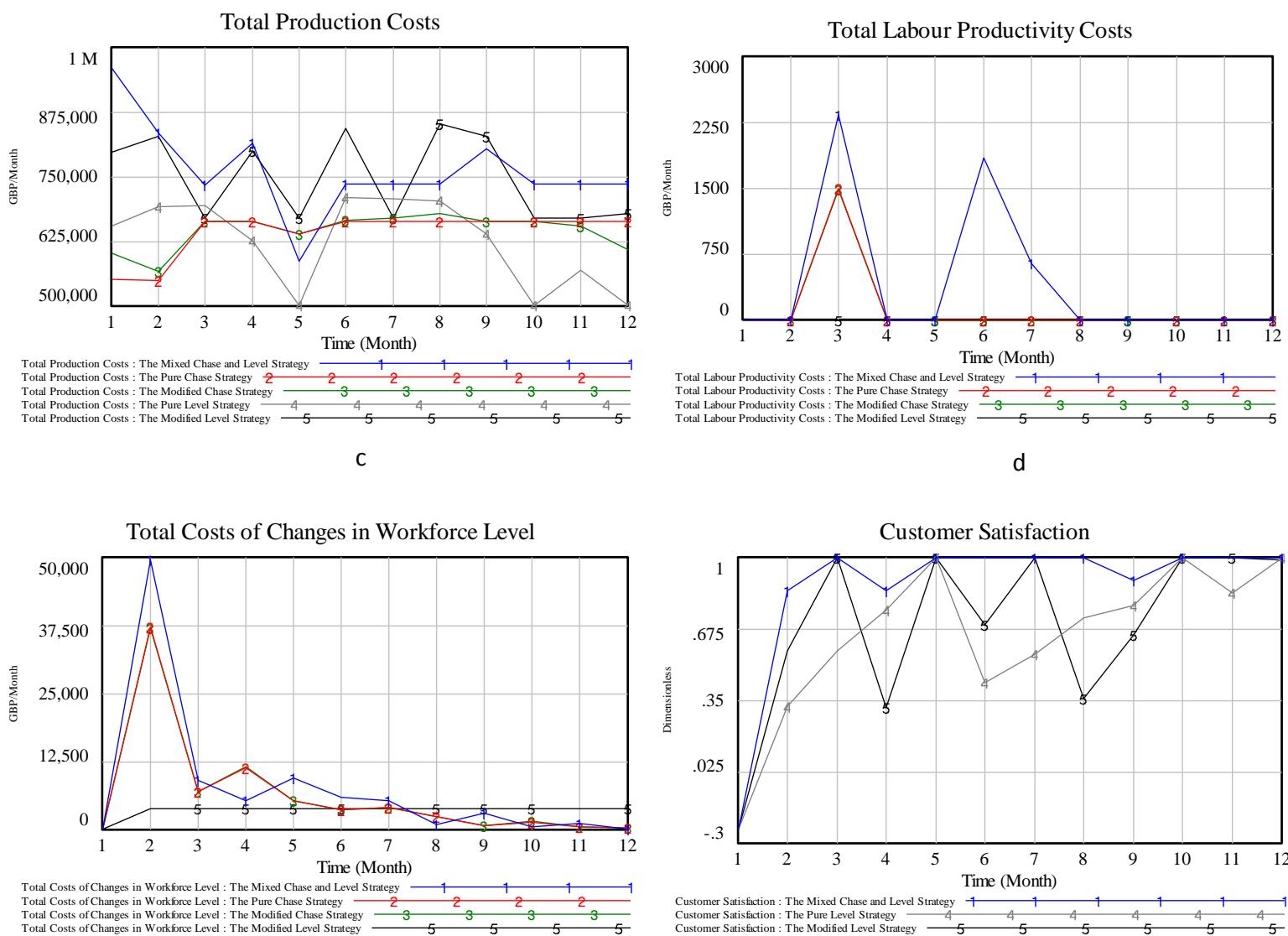

f
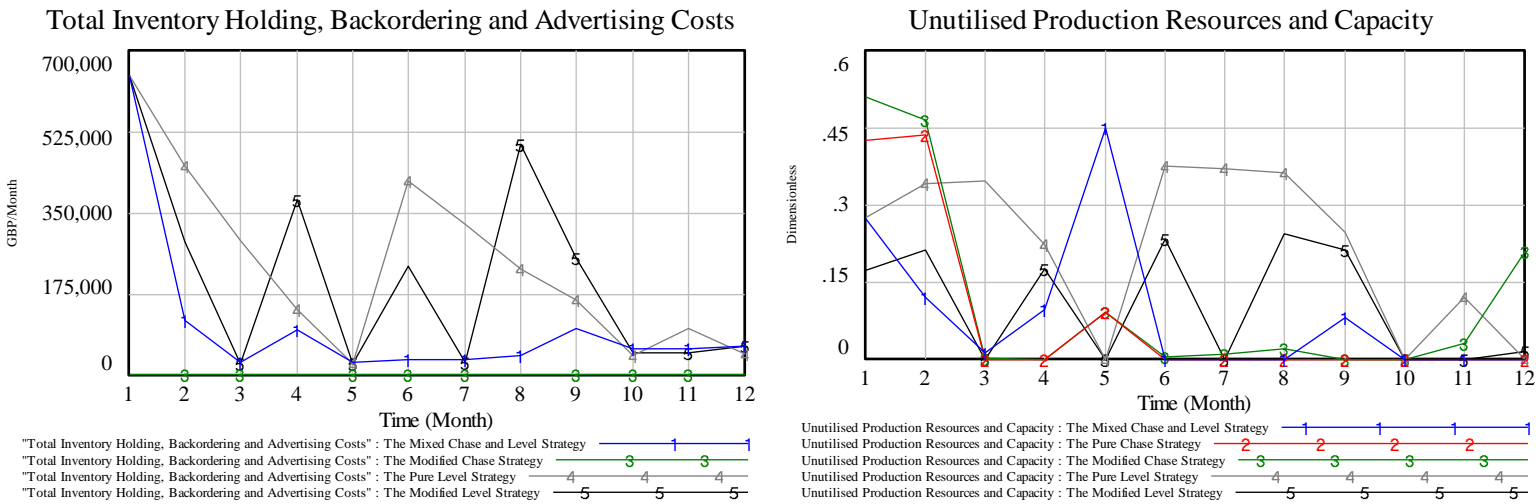

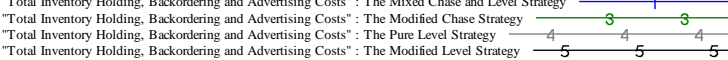

g

$\mathrm{h}$

Figure 4: SD simulation results for different criteria

When total revenue criterion is considered, the mixed chase and level strategy stays in first place in simulation modelling as well. But, now, the modified level and the modified chase strategies generate the second and the third highest revenues respectively not the pure chase and modified chase strategies. This is normally attributed to whether the backorder quantity has surpassed the threshold level or not, and the degree to which it has gone beyond or fallen below this threshold, which in regard to fundamental differences between simulation and mathematical programming can 
have varying impact on product price, advertising costs, new orders inflow and consequently on total revenue. Level strategies rank does not change.

Table 7: Comparison of APP strategies with regard to cumulative/average values of each criterion in simulation modelling

\begin{tabular}{|c|c|c|c|c|c|c|c|c|}
\cline { 2 - 8 } \multicolumn{1}{c|}{} & \multicolumn{1}{|c|}{$\begin{array}{c}\text { Criteria } \\
\begin{array}{c}\text { APP } \\
\text { strategy }\end{array}\end{array} \begin{array}{c}\text { Total } \\
\text { revenue } \\
\text { (cumulative) }\end{array}$} & $\begin{array}{c}\text { Total } \\
\text { production } \\
\text { costs } \\
\text { (cumulative) }\end{array}$ & $\begin{array}{c}\text { Total labour } \\
\text { productivity } \\
\text { costs } \\
\text { (cumulative) }\end{array}$ & $\begin{array}{c}\text { Total costs of } \\
\text { changes in } \\
\text { workforce } \\
\text { level } \\
\text { (cumulative) }\end{array}$ & $\begin{array}{c}\text { Total } \\
\text { Customer } \\
\text { satisfaction } \\
\text { (average) }\end{array}$ & $\begin{array}{c}\text { holding, } \\
\text { hockordering } \\
\text { and } \\
\text { advertising } \\
\text { costs } \\
\text { (cumulative) }\end{array}$ & $\begin{array}{c}\text { Unutilised } \\
\text { production } \\
\text { resources } \\
\text { and capacity } \\
\text { (average) }\end{array}$ & $\begin{array}{c}\text { Total profit } \\
\text { (cumulative) }\end{array}$ \\
\hline $\begin{array}{c}\text { The } \\
\text { mixed } \\
\text { chase } \\
\text { and level }\end{array}$ & 14947418 & 9151349.625 & 4805.743 & 90526.55483 & 0.862854167 & 1305343 & 0.085686667 & 4395393 \\
\hline $\begin{array}{c}\text { The pure } \\
\text { chase }\end{array}$ & 12616745 & 7702181.5 & 1486.35571 & 73853.40326 & 1 & 0 & 0.079329 & 4839223 \\
\hline $\begin{array}{c}\text { The } \\
\text { modified } \\
\text { chase }\end{array}$ & 13101284 & 7736273.25 & 1486.35571 & 73848.76196 & 1 & 12764.07 & 0.11169 & 5276911 \\
\hline $\begin{array}{c}\text { The pure } \\
\text { level }\end{array}$ & 11527630 & 7496958.281 & 0 & 0 & 0.646075833 & 2878571 & 0.221201667 & 1152100 \\
\hline $\begin{array}{c}\text { The } \\
\text { modified } \\
\text { level }\end{array}$ & 13695582 & 8975700.125 & 0.03983 & 43490.73156 & 0.695148333 & 2542860 & 0.105066667 & 2133531 \\
\hline
\end{tabular}

The lowest total production costs belongs to the pure level strategy in simulation modelling as well. However, instead of modified level strategy, in simulation modelling the pure chase strategy produces the second lowest total production costs. This is not unexpected because by increasing the production volume by allowing a controlled rate of hiring and lay off, backorder quantity can drop which causes an increase in new orders inflow and another increase in production amount and thus total production costs. Similar to mathematical modelling results, a chase strategy, i.e. the modified chase strategy has the third lowest total production costs.

Both level strategies stay in the first place when total labour productivity costs measure is taken into account, which is consistent with the mathematical modelling findings. However, now, both chase strategies come in third place not the mixed chase and level policy. This is also quite possible since as is evident from Table 7, by applying the mixed chase and level strategy, workforce level shows the highest oscillation which is resulted from constant pricing and advertising policies for adjusting demand (new orders inflow) that in turn leads to higher oscillations in demand level and consequently in workforce level especially when there is no upper bounds on hiring and lay off rates. Please note that as already stated only positive deviations from standard production times are considered. 
Ranking of APP strategies on the basis of total costs of changes in workforce level is almost the same as ranking obtained for total labour productivity costs criterion, and the same reasoning is applied. In both simulation modelling and mathematical programming, based on total costs of changes in workforce level, the pure level and modified level strategies top the list respectively. But, in simulation model, total costs of changes in workforce for the mixed chase and level strategy is even higher than that of both chase strategies which arises from higher variations in adjusted demand quantity and therefore production volumes which finally leads to higher variations in workforce level.

The rankings of APP policies regarding the customer satisfaction and total inventory holding, backordering and advertising costs criteria in simulation modelling thoroughly conform to that of mathematical modelling.

Finally, when optimum utilisation of production resources and capacity is considered, in both simulation modelling and mathematical modelling, the pure chase strategy performs best and the pure level plan remains at the bottom of the list. The performance of modified chase strategy deteriorates significantly in comparison with its performance in mathematical modelling most likely due to allowing subcontracting in the simulation model.

\section{Conclusions and directions for future research}

The present study proposed a framework based on a set of stochastic, nonlinear, multi-objective optimisation models to evaluate the performance of various APP strategies under uncertainty in soft drink industry, where the customer demand was regarded as the main source of uncertainty. In the first stage, a novel, precise, stochastic, nonlinear, multi-objective optimisation decision making model was constructed for APP based on the mixed chase and level strategy to consider APP from a holistic view. Then, the relevant models for other APP strategies such as pure chase, pure level, modified chase and modified level were derived from the model that was developed for the mixed chase and level strategy. Different APP strategies were compared with regard to criteria/objectives like total profit, total revenue, total production costs and total labour productivity costs.

The MCDM methods AVF, TOPSIS and VIKOR were used to rank various APP strategies regarding different criteria, and then the rankings of different methods were aggregated by computing the average of the ranks and by Borda and Copeland methods.

With regard to initial criteria weights, the pure chase and the modified chase strategies had the best performance in general after aggregating the rankings of different methods, followed by the pure level strategy.

However, the sensitivity analysis showed that altering the criteria weights can change ranking of APP strategies. Chase strategies performed well when the importance weights of $Z_{3}$ and $Z_{4}$ (total labour 
productivity costs and total costs of changes in workforce level respectively) increase. On the other hand, reducing the weights of $Z_{1}, Z_{5}, Z_{6}$ and $Z_{7}$ (total revenue, customer satisfaction degree, total inventory holding, backordering and advertising costs and unutilised production resources and capacity respectively), where level strategies performed poorly, significantly improves the ranking of these strategies. Assigning higher weights to $Z_{1}$ (total revenue) in which the mixed chase and level strategy has the best performance, changes the rankings in favour of this strategy.

The performance of APP strategies was also simulated by an integrated DES-SD methodology, and the results were compared to those of mathematical models. On the whole, simulation modelling approved most of the results obtained by mathematical modelling.

The research can be extended in several directions in the future, mainly:

- The present study was conducted in an industry which combines both capital-intensiveness and labour-intensiveness features. Case studies from more labour-intensive industries, especially in chase strategy cases, would produce more informative results/findings.

- The interface between operations management and marketing management has been a growing area of research. To the best of the authors' knowledge, there is no published work on evaluating APP strategies from marketing management viewpoint. This is especially true regarding the fact that the demand management mechanisms embedded in level strategies act by applying pricing and advertising options that normally are considered as marketing management mechanisms as well. 


\section{Appendix A: Concise re-presentation of the model developed for the fundamental mixed chase}

and level strategy in Jamalnia et al. (2017)

\section{Notations}

\subsection{Decision variables}

In notations definition for decision variables the subscripts $r, e, n, s$ and superscript $t$ stand for regular shift, extra shift, product $n$, scenario $s$ and time period $t$ respectively. $D, Q, B, I, H$ and $L$ denote product demand (unadjusted demand), production volume, backorder, inventory, hiring and lay off respectively. $P R, A C, P T$ and $P C$ show product price, advertising costs, production time and production capacity respectively.

\subsection{Parameters/constants}

$C, F, W$ and $v$ represent cost, time required to produce the first unit of a product, workforce level and warehouse space respectively. $C P R, P P R, F P R, F A C, S P T, T P C, M U$ and $M C$ denote the coefficient in the equation for product price, the parameter in the equation for product price, fixed price, fixed advertising costs, standard production time, total production capacity, hours of machine usage per unit of a product and machine capacity respectively.

Similar subscripts are also used for parameters/constants except that $s$ in the cost coefficient of the decision variable which shows subcontracting stands for subcontracting not scenario $s$. In addition, $u$ as subscript of the product demand denotes unadjusted demand, and $w$ stands for workers in salary cost parameters. The lower cases of the notations which were introduced for decision variables are used in subscript of the constants/parameters to be representative of those variables correspondingly. Max in subscripts denote the maximum values of the constants/parameters.

$P$ with subscript $s$ shows the probability associated with scenario $s$, and $p$ in subscript of production costs denotes production.

$\sigma$ is the regulator parameter, and $a, b$ and $c$ are constant terms in relevant equations. 


\section{Objectives}

\subsection{Maximise total revenue}

$\operatorname{Max} Z_{1}^{S}=\sum_{n=1}^{N} \sum_{t=1}^{T}\left(I_{n s}^{t-1}+Q_{r n s}^{t}+Q_{e n s}^{t}+S_{n s}^{t}-I_{n s}^{t}\right) P R_{n s}^{t}$

\subsection{Minimise total production costs}

Three items: all production costs except worker salaries in regular shift and extra shift, worker salaries in regular shift and extra shift and subcontracting costs are included in total production costs.

$\operatorname{Min} Z_{2}^{S}$

$=\sum_{n=1}^{N} \sum_{t=1}^{T} C_{p n}^{t}\left(Q_{r n s}^{t}+Q_{e n s}^{t}\right)$

$+\sum_{n=1}^{N} \sum_{t=1}^{T}\left(Q_{r n s}^{t-1} P T_{r n s}^{t}+F_{r n}\left(\left|Q_{r n s}^{t}-Q_{r n s}^{t-1}\right|+\varepsilon\right)^{b_{r}} \max \left(\left(Q_{r n s}^{t}-Q_{r n s}^{t-1}\right), 0\right)\right.$

$\left.-\max \left(\left(Q_{r n s}^{t-1}-Q_{r n s}^{t}\right), 0\right) P T_{r n s}^{t-1}\right) C_{r w n}^{t}$

$+\sum_{n=1}^{N} \sum_{t=1}^{T}\left(Q_{\text {ens }}^{t-1} P T_{\text {ens }}^{t}+F_{\text {en }}\left(\left|Q_{\text {ens }}^{t}-Q_{\text {ens }}^{t-1}\right|+\varepsilon\right)^{b_{e}} \max \left(\left(Q_{\text {ens }}^{t}-Q_{\text {ens }}^{t-1}\right), 0\right)\right.$

$\left.-\max \left(\left(Q_{\text {ens }}^{t-1}-Q_{\text {ens }}^{t}\right), 0\right) P T_{\text {ens }}^{t-1}\right) C_{\text {ewn }}^{t}$

$+\sum_{n=1}^{N} \sum_{t=1}^{T} C_{s n}^{t} S_{n s}^{t}$

\subsection{Minimise total labour productivity costs}

This objective function is to minimise the positive deviations from the standard production time for both existing workforce, due to frequent lay-offs, and therefore workers motivation decline, and newly hired labour force because of the learning time required to reach a normal productivity level equivalent to the productivity of experienced labour. 
$\operatorname{Min} \mathrm{Z}_{3}^{S}$

$=\sum_{n=1}^{N} \sum_{t=1}^{T}\left(\max \left(P T_{r n s}^{t}-S P T_{r n}, 0\right) Q_{r n s}^{t-1}\right) C_{r w n}^{t}+\left(\max \left(P T_{e n s}^{t}-S P T_{e n}, 0\right) Q_{e n s}^{t-1}\right) C_{e w n}^{t}$

$+\sum_{n=1}^{N} \sum_{t=1}^{T}\left(\max \left(F_{r n}\left(\left|Q_{r n s}^{t}-Q_{r n s}^{t-1}\right|+\varepsilon\right)^{b_{r}}-S P T_{r n}, 0\right) \max \left(Q_{r n s}^{t}-Q_{r n s}^{t-1}, 0\right)\right) C_{r w n}^{t}$

$+\sum_{n=1}^{N} \sum_{t=1}^{T}\left(\max \left(F_{e n}\left(\left|Q_{\text {ens }}^{t}-Q_{\text {ens }}^{t-1}\right|+\varepsilon\right)^{b_{e}}\right.\right.$

$\left.-S P T_{e n}, 0\right) \max \left(Q_{\text {ens }}^{t}\right.$

$\left.\left.-Q_{\text {ens }}^{t-1}, 0\right)\right) C_{\text {ewn }}^{t}$

2.4. Minimise the changes in workforce level

$\operatorname{Min} Z_{4}^{s}=\sum_{t=1}^{T}\left(C_{r h}^{t} H_{r s}^{t}+C_{r l}^{t} L_{r s}^{t}+C_{e h}^{t} H_{e s}^{t}+C_{e l}^{t} L_{e s}^{t}\right)$

\subsection{Maximise customer satisfaction}

$\operatorname{Max} Z_{5}^{S}=\sum_{n=1}^{N} \sum_{t=1}^{T}\left(1-\frac{B_{n s}^{t}}{D_{n s}^{t}}\right) / N T$

2.6. Minimise total inventory holding, backordering and advertising costs

$\operatorname{Min} Z_{6}^{s}=\sum_{n=1}^{N} \sum_{t=1}^{T}\left(C_{i n}^{t} I_{n s}^{t}+C_{b n}^{t} B_{n s}^{t}\right)+\sum_{n=1}^{N} \sum_{t=1}^{T} A C_{n s}^{t}$

2.7. Minimise unutilised production resources and capacity

$\operatorname{Min} Z_{7}^{S}=\sum_{n=1}^{N} \sum_{t=1}^{T}\left[\left(\frac{S_{n s}^{t}}{Q_{r n s}^{t}+Q_{e n s}^{t}}\right)+\left(1-\frac{Q_{r n s}^{t}}{P C_{r n}^{t}}\right)+\left(1-\frac{Q_{e n s}^{t}}{P C_{e n}^{t}}\right)\right] / 3 N T$

The expected value for objective $k, E\left(Z_{k}\right)$, is then obtained as follows:

$E\left(Z_{k}\right)=\sum_{S=1}^{S} P_{S} Z_{k}^{S}$

Where, $S$ is the total number of scenarios. 


\section{Constraints}

\subsection{Capacity constraints}

Production capacities assigned to different products are regarded as first stage decision variables, i.e. decisions that need to be made before the uncertain outcomes are revealed.

$Q_{r n s}^{t} \leq P C_{r n}^{t}$

$Q_{e n s}^{t} \leq P C_{e n}^{t}$

$\sum_{n=1}^{N} \sum_{t=1}^{T}\left(P C_{r n}^{t}+P C_{e n}^{t}\right) \leq T P C$

\subsection{Constraints for the demand management options}

The common demand management options are pricing, advertising, backordering and introducing complementary products. Since launching new products requires establishing new production facilities/production lines, only the first three options are considered in present study.

By applying pricing and advertising policies, business managers can shift the demand from peak periods to off-peak periods.

$$
\begin{aligned}
\left(B_{n s}^{t-1}-B_{n \delta}^{t-1}\right) P & R_{n s}^{t} \\
& =\left(\max \left(B_{n s}^{t-1}-B_{n \delta}^{t-1}, 0\right)\right) F P R_{n s}^{t}+\left(\min \left(B_{n s}^{t-1}-B_{n \delta}^{t-1}, 0\right)\right)\left(C P R_{n} B_{n s}^{t-1}\right. \\
& \left.+P P R_{n}\right) \quad \forall n, \forall t, \forall s \in\{L, A\}
\end{aligned}
$$

$$
\begin{aligned}
\left(B_{n s}^{t-1}-B_{n \delta}^{t-1}\right) P & R_{n H}^{t} \\
& =\left(\min \left(B_{n s}^{t-1}-B_{n \delta}^{t-1}, 0\right)\right) F P R_{n s}^{t}+\left(\max \left(B_{n s}^{t-1}-B_{n \delta}^{t-1}, 0\right)\right)\left(C P R_{n} B_{n s}^{t-1}\right. \\
& \left.+P P R_{n}\right)
\end{aligned}
$$

$\left(B_{n s}^{t-1}-B_{n \delta}^{t-1}\right) A C_{n s}^{t}$

$$
\begin{aligned}
& =\left(\max \left(B_{n s}^{t-1}-B_{n \delta}^{t-1}, 0\right)\right) F A C_{n s}^{t} \\
& +\left(\min \left(B_{n s}^{t-1}-B_{n \delta}^{t-1}, 0\right)\right)\left(a_{A C_{n}}+\frac{b_{A C_{n}}}{\sigma_{A C_{n}} B_{n s}^{t-1}+c_{A C_{n}}}\right) \quad \forall n, \forall t, \forall \in\{L, A\}
\end{aligned}
$$




$$
\begin{aligned}
& \left(B_{n s}^{t-1}-B_{n \delta}^{t-1}\right) A C_{n H}^{t} \\
& =\left(\min \left(B_{n s}^{t-1}-B_{n \delta}^{t-1}, 0\right)\right) F A C_{n s}^{t} \\
& +\left(\max \left(B_{n s}^{t-1}-B_{n \delta}^{t-1}, 0\right)\right)\left(a_{A C_{n}}+\frac{b_{A C_{n}}}{\sigma_{A C_{n}} B_{n s}^{t-1}+c_{A C_{n}}}\right) \\
& D_{n s}^{t}=D_{u n s}^{t}\left(1+\sigma_{D_{n L A}} \max \left(\frac{\frac{A C_{n s}^{t}}{P R_{n s}^{t}}-\frac{A C_{n_{\delta}}^{t}}{P R_{n_{\delta}}^{t}}}{\frac{A C_{n_{\delta}}^{t}}{P R_{n_{\delta}}^{t}}}, 0\right)\right) \\
& D_{n H}^{t}=D_{u n H}^{t}\left(1+\sigma_{D_{n H}} \min \left(\frac{\frac{A C_{n H}^{t}}{P R_{n H}^{t}}-\frac{A C_{n_{\delta-1}}^{t}}{P R_{n_{\delta-1}}^{t}}}{\frac{A C_{n_{\delta-1}}^{t}}{P R_{n_{\delta-1}}^{t}}}, 0\right)\right)
\end{aligned}
$$

\subsection{Production and inventory balance}

$$
\begin{array}{ll}
I_{n s}^{t-1}-B_{n s}^{t-1}+Q_{r n s}^{t}+\left(\frac{\max \left(D_{n s}^{t}+B_{n s}^{t-1}-P C_{r n}^{t}-I_{n s}^{t-1}, 0\right)}{\left(\max \left(D_{n s}^{t}+B_{n s}^{t-1}-P C_{r n}^{t}-I_{n s}^{t-1}, 0\right)+\varepsilon\right)}\right)\left(Q_{e n s}^{t}+S_{n s}^{t}\right)- & D_{n s}^{t} \\
=I_{n s}^{t}-B_{n s}^{t} & \forall n, \forall t, \forall s \quad(19) \\
B_{n s}^{t} \leq B_{n s \max }^{t} & \forall n, \forall t, \forall s \quad(20) \\
S_{n s}^{t} \leq S_{n s \max }^{t} & \forall n, \forall t, \forall s \quad(21)
\end{array}
$$

\subsection{Recruitment constraints}

The learning curve effect is considered in the constructed APP model to better reflect the worker experience factor in computing the required labour-hours, which is embedded in following constraints.

$$
\begin{aligned}
H_{r s}^{t} & =\sum_{n=1}^{N} F_{r n}\left(\left|Q_{r n s}^{t}-Q_{r n s}^{t-1}\right|+\varepsilon\right)^{b_{r} \max }\left(\left(Q_{r n s}^{t}-Q_{r n s}^{t-1}\right), 0\right) \\
L_{r s}^{t} & =\sum_{n=1}^{N} \max \left(\left(Q_{r n s}^{t-1}-Q_{r n s}^{t}\right), 0\right) P T_{r n s}^{t-1} \\
L_{r n s}^{t} & =\max \left(\left(Q_{r n s}^{t-1}-Q_{r n s}^{t}\right), 0\right) P T_{r n s}^{t-1}
\end{aligned}
$$




$$
\begin{aligned}
& P T_{r n s}^{t}=a_{P T_{r n}}+\ln \left(b_{P T_{r n}} L_{r n s}^{t}+c_{P T_{r n}}\right) \\
& H_{e s}^{t}=\sum_{n=1}^{N} F_{e n}\left(\left|Q_{e n s}^{t}-Q_{e n s}^{t-1}\right|+\varepsilon\right)^{b_{e}} \max \left(\left(Q_{\text {ens }}^{t}-Q_{\text {ens }}^{t-1}\right), 0\right) \\
& L_{e s}^{t}=\sum_{n=1}^{N} \max \left(\left(Q_{\text {ens }}^{t-1}-Q_{\text {ens }}^{t}\right), 0\right) P T_{\text {ens }}^{t-1} \\
& L_{\text {ens }}^{t}=\max \left(\left(Q_{\text {ens }}^{t-1}-Q_{\text {ens }}^{t}\right), 0\right) P T_{\text {ens }}^{t-1} \\
& P T_{e n s}^{t}=a_{P T_{e n}}+\ln \left(b_{P T_{e n}} L_{e n s}^{t}+c_{P T_{e n}}\right) \\
& \sum_{n=1}^{N} Q_{r n s}^{t-1} P T_{r n s}^{t}+H_{r s}^{t}-L_{r s}^{t} \leq W_{r s \max }^{t} \\
& \sum_{n=1}^{N} Q_{e n s}^{t-1} P T_{e n s}^{t}+H_{e s}^{t}-L_{e s}^{t} \leq W_{e s \max }^{t}
\end{aligned}
$$

\subsection{Machine capacity and warehouse space}

$\sum_{n=1}^{N} M U_{n}\left(Q_{r n s}^{t}+Q_{\text {ens }}^{t}\right) \leq M C_{\text {max }}^{t}$

$\sum_{n=1}^{N} v_{n} I_{n s}^{t} \leq V_{\max }^{t}$

$Q_{r n s}^{t}, Q_{e n s}^{t}, S_{n s}^{t}, B_{n s}^{t}, I_{n s}^{t}, P C_{r n}^{t}, P C_{e n}^{t}, P T_{r n s}^{t}, P T_{e n s}^{t}, H_{r s}^{t}, L_{r s}^{t}, L_{r n s}^{t}, H_{e s}^{t}, L_{e s}^{t}, L_{e n s}^{t}, D_{n s}^{t}, P R_{n s}^{t}$, $A C_{n s}^{t} \geq 0$ 


\section{References}

Baines, T.S. and Harrison, D.K. (1999). An opportunity for system dynamics in manufacturing system modelling. Production Planning \& Control, 10 (6), 542-552.

Buxey, G. (1990). The myth of aggregate planning. Production Planning \& Control, 1 (4), 222-234.

Buxey, G. (1995). A managerial perspective on aggregate planning. International Journal of Production Economics, 41 (1-3), 127-133.

Buxey, G. (2003). Strategy not tactics drives aggregate planning. International Journal of Production Economics, 85(3), 331-346.

Buxey, G. (2005). Aggregate planning for seasonal demand: reconciling theory with practice. International Journal of Operations and Production Management, 25 (11), 1083-1100.

Bowman, E.H. (1956). Production scheduling by the transportation method of linear programming. Operations Research, 4(1), 100-103.

Chen, Y.K. and Liao, H.C. (2003). An investigation on selection of simplified aggregate production planning strategies using MADM approaches. International Journal of Production Research, 41(14), 3359-3374.

Dubois, F.L. and Oliff, M.D. (1991). Aggregate production planning in practice. Production and Inventory Management Journal, 32 (3), 26-30.

Fiasché, M., Ripamonti, G., Sisca, F.G., Taisch, M. and Tavola, G. (2016). A Novel hybrid fuzzy multiobjective linear programming method of aggregate production planning. In S. Bassis, A. Esposito, F. Carlo Morabito \& E. Pasero (Eds.), Advances in Neural Networks (pp. 489-501). Switzerland: Springer International Publishing.

Ghasemy Yaghin, R., Torabi, S.A. and Fatemi Ghomi, S.M.T. (2012). Integrated markdown pricing and aggregate production planning in a two echelon supply chain: A hybrid fuzzy multiple objective approach. Applied Mathematical Modelling, 36(12), 6011-6030.

Gen, M., Tsujimura, Y. and Ida, K. (1992). Method for solving multi-objective aggregate production planning problem with fuzzy parameters. Computers and Industrial Engineering, 23(I-4), 117-120.

Gholamian, N., Mahdavi,I, Tavakkoli-Moghaddam, R. and Mahdavi-Amiri, N. (2015). Comprehensive fuzzy multi-objective multi-product multi-site aggregate production planning decisions in a supply chain under uncertainty. Applied Soft Computing, 37(2015), 585-607.

Gholamian, N., Mahdavi, I. and Tavakkoli-Moghaddam, R. (2016). Multiobjective multi-product multi-site aggregate production planning in a supply chain under uncertainty: fuzzy multi-objective optimisation. International Journal of Computer Integrated Manufacturing, 29(2), 149-165.

Gulsun, B., Tuzkaya, G., Tuzkaya, U.R. and Onut, S. (2009). An aggregate production planning strategy selection methodology based on linear physical programming. International Journal of Industrial Engineering, 16 (2), 135-146.

Holt, C.C., Modigliani, F. and Simon, H.A. (1955). Linear decision rule for production and employment scheduling. Management Science, 2(1), 1-30.

Holt, C.C., Modigliani, F. and Muth, J.F. (1956). Derivation of a linear decision rule for production and employment. Management Science, 2(2), 159-177.

Jamalnia, A., Yang, J.B., Feili, A., Xu, D.L. and Jamali, G. (2019). Aggregate production planning under uncertainty: a comprehensive literature survey and future research directions. The International Journal of Advanced Manufacturing Technology. DOI: 10.1007/s00170-018-3151-y.

Jamalnia, A., Yang, J.B., Xu, D.L. and Feili, A. (2017). Novel decision model based on mixed chase and level strategy for aggregate production planning under uncertainty: case study in beverage industry. Computers \& Industrial Engineering, 114 (2017), 54-68.

Jamalnia, A. and Feili, A. (2013). A simulation testing and analysis of aggregate production planning strategies. Production Planning \& Control, 24(6), 423-448.

Kalaf, B.A., Abu Bakar, R., Soon, L.L., Bin Monsi, M., Bakheet, A.J.K. and Abbas, I.T. (2015). A modified fuzzy multi-objective linear programming to solve aggregate production planning. International Journal of Pure and Applied Mathematics, 104(3), 339-352. 
Liao, H.C., Chen, Y.K. and Chang, H.H. (2011). The APP strategies selected in SCM of the hospital. International Journal of Services Technology and Management, 15(3-4), 298-313.

Lee, W.B. and Khumawala, B.M. (1974). Simulation testing of aggregate production planning models in an implementation methodology. Management Science, 20(6), 903-911.

Lee, Y.Y. (1990). Fuzzy sets theory approach to aggregate production planning and inventory control. PhD. Kansas State University.

Madadi, N. and Wong, K.Y. (2014). A multi-objective fuzzy aggregate production planning model considering real capacity and quality of products. Mathematical Problems in Engineering, 2014(2014), 1-15.

Mezghani, M., Loukil, T. and Aouni, B. (2011). Manager preferences modelling for stochastic aggregate planning. In T. Trzaskalik \& T. Wachowicz (Eds.), Multiple Criteria Decision Making '10-11 (pp. 149-162). Katowice: Publisher of The University of Economics in Katowice.

Miettinen, K. and Mäkelä, M.M. (1995). Interactive bundle-based method for non-differentiable multi-objective optimization: NIMBUS. Optimization, 34(3), 231-246.

Miettinen, K. and Mäkelä, M.M. (2006). Synchronous approach in interactive multi-objective optimization. European Journal of Operational Research, 170(3), 909-922.

Nowak, M. (2013). An interactive procedure for aggregate production planning. Croatian Operational Research Review, 4(1), 247-257.

Rakes, T.R., Franz, L.S. and Wynne, A.J. (1984). Aggregate production planning using chanceconstrained goal programming. International Journal of Production Research, 22(4), 673-684.

Reid, R.D. and Sanders., N.R. (2009). Operations management. New York: John Wiley and Sons.

Schroeder, R.G. (2003). Operations management, contemporary concepts and cases. New York: McGraw-Hill.

Sisca, F.G., Fiasché, M. and Taisch, M. (2015). A novel hybrid modelling for aggregate production planning in a reconfigurable assembly unit for optoelectronics. In S. Arik, T. Huang, W.K. Lai \& Q. Liu (Eds.), National Information Processing (pp. 571-582). Switzerland: Springer International Publishing. Slack, N., Brandon-Jones, A. and Johnston, R. (2013). Operations management. Harlow: Pearson Education Limited.

Shi, Y. and Haase, C. (1996). Optimal trade-offs of aggregate production planning with multiple objective and multi-capacity demand levels. International Journal of Operations and Quantitative Management, 2(2), 127-143.

Thompson, S.D., Wantanabe, D.T. and Davis, W.J. (1993). A comparative study of aggregate production planning strategies under conditions of uncertainty and cyclic product demands. International Journal of Production Research, 31(8), 1957-1979.

Wang, R.C. and Fang, H.H. (2001). Aggregate production planning with multiple objectives in a fuzzy environment. European Journal of Operational Research, 133(3), 521-536.

Wang, R.C. and Liang, T.F. (2004). Application of fuzzy multi-objective linear programming to aggregate production planning. Computers \& Industrial Engineering, 46(1), 17-41.

Zaidan, A.A., Atiya, B., Abu Bakar, M.R. and Zaidan, B.B. (2017). A new hybrid algorithm of simulated annealing and simplex downhill for solving multiple-objective aggregate production planning on fuzzy environment. Neural Computing and Applications. DOI: 10.1007/s00521-017-3159-5. 


\section{Appendix B: Supplementary Materials}

\section{PART 1: The data tables}

\section{The input data}

The mathematical models for APP strategies are implemented in ZamZam Group based on the following conditions:

- Carbonated soft drinks in $300 \mathrm{ml}$ bottles in three flavours Cola, Orange and Lemonade are considered as a family of products in order to run APP process. The multiproduct APP decision making problem is conducted over a span of 12 months which includes 4 time periods, i.e. 4 seasons to reflect the seasonality of the forecasted demand.

- The unadjusted forecasted demand for each product under different scenarios, cost figures and other input data are presented in Tables 1, 2 and 3.

- Maximum total capacity allocated to all products over the planning horizon $T$ is $138,670,042$ bottles.

- The initial inventories for products 1, 2 and 3 are 208,796, 102,698 and 38,113 bottles respectively.

- There is no initial backorder.

- Previous time-period production in regular shift at the beginning of the planning horizon for products 1,2 and 3 is 10,278,331, 2,944,435 and 907,620 bottles respectively.

- Previous time-period production in extra shift at the beginning of the planning horizon for all products is zero.

- The time required to produce first unit of all products in the automated production line in all time periods by newly employed workers is 0.001088 man-hour/bottle in both regular shift and extra shift, and the standard production time for all products in both regular shift and extra shift is estimated as 0.00075 man-hour/bottle.

- The upper bound on workforce level in all time periods for both regular shift and extra shift is 17021 man-hour.

- The learning rate in both regular shift and extra shift is supposed to be 0.95 .

- $\left(C P R_{n}, P P R_{n}\right)$ for products 1,2 and 3 are computed through linear regression method by using past data as $(0.00000002028,0.0894),(0.00000004092,0.0897)$ and $(0.0000001287$, 0.0908) correspondingly.

- The approximation for $\left(a_{A C_{n}}, b_{A C_{n}}, c_{A C_{n}}\right)$, are respectively $(-37,749,178,519,000,000$, $2,513,079),(-21,987,56,251,340,000,1,459,053)$ and $(-6,469,5,122,434,000,427,396)$ for products 1,2 and 3 by applying curve fitting methods.

- The approximated values for $\left(a_{P T_{n}}, b_{P T_{n}}, c_{P T_{n}}\right)$ in both regular shift and extra shift for products 1,2 and 3 are $(4.550524,0.000000001442927,0.01056907)$, (4.546664, $0.000000002897013,0.01060994)$ and $(4.564944,0.000000008527615,0.01041776)$ respectively by using curve fitting methods.

- The probability of low, average and high demand scenarios are estimated by marketing managers as $0.30,0.50$ and 0.20 respectively using the past demand data. 
- $\sigma_{D_{n s}}$ and $\sigma_{A C_{n}}$ are intuitively determined as 0.20 and 1 respectively through a trial and error process by running the model several times with regard to different values of these parameters.

- All monetary values, e.g. costs, revenues, profits, etc. are in British Pound (GBP).

Table 1: Unadjusted forecasted product demand (in bottles)

\begin{tabular}{|c|c|c|c|c|c|}
\cline { 3 - 6 } \multicolumn{2}{c|}{} & \multicolumn{4}{c|}{ Time period } \\
\hline \multirow{3}{*}{ Product } & Scenario & 1 & 2 & 3 & 4 \\
\hline & L & 9747943 & 11123480 & 8120967 & 6065191 \\
\cline { 2 - 6 } & A & 14982840 & 20343160 & 16926800 & 11414810 \\
\cline { 2 - 6 } & H & 15296181 & 18803319 & 12973106 & 9525384 \\
\hline \multirow{3}{*}{2} & L & 5021774 & 6134489 & 4343471 & 3264113 \\
\cline { 2 - 6 } & A & 7812561 & 10169900 & 8920985 & 5967746 \\
\cline { 2 - 6 } & H & 7674811 & 8310541 & 6449115 & 5029168 \\
\hline \multirow{3}{*}{3} & L & 1561509 & 1909242 & 1354043 & 1021289 \\
\cline { 2 - 6 } & A & 2452971 & 3271535 & 2770720 & 1836216 \\
\cline { 2 - 6 } & H & 2388680 & 2915203 & 2038001 & 1512800 \\
\hline
\end{tabular}

Table 2: Cost figures (in GBP)

\begin{tabular}{|c|c|c|c|c|c|c|c|}
\hline Product & Time period & $C_{p n}^{t}$ & $C_{r w n}^{t}$ & $C_{e w n}^{t}$ & $C_{s n}^{t}$ & $C_{b n}^{t}$ & $C_{\text {in }}^{t}$ \\
\hline \multirow{4}{*}{1} & 1 & 0.0638 & 0.8654 & 0.9952 & 0.0721 & 0.0731 & 0.000715 \\
\cline { 2 - 8 } & 2 & 0.0650 & 0.8654 & 0.9952 & 0.0735 & 0.0745 & 0.000875 \\
\cline { 2 - 8 } & 3 & 0.0663 & 0.8654 & 0.9952 & 0.0750 & 0.0760 & 0.000595 \\
\cline { 2 - 8 } & 4 & 0.0677 & 0.8654 & 0.9952 & 0.0765 & 0.0775 & 0.000455 \\
\hline \multirow{4}{*}{2} & 1 & 0.0638 & 0.8654 & 0.9952 & 0.0721 & 0.0731 & 0.000715 \\
\cline { 2 - 8 } & 2 & 0.0650 & 0.8654 & 0.9952 & 0.0735 & 0.0745 & 0.000875 \\
\cline { 2 - 8 } & 3 & 0.0663 & 0.8654 & 0.9952 & 0.0750 & 0.0760 & 0.000595 \\
\hline \multirow{3}{*}{3} & 4 & 0.0677 & 0.8654 & 0.9952 & 0.0765 & 0.0775 & 0.000455 \\
\cline { 2 - 8 } & 1 & 0.0638 & 0.8654 & 0.9952 & 0.0721 & 0.0731 & 0.000715 \\
\cline { 2 - 8 } & 2 & 0.0650 & 0.8654 & 0.9952 & 0.0735 & 0.0745 & 0.000875 \\
\cline { 2 - 8 } & 3 & 0.0663 & 0.8654 & 0.9952 & 0.0750 & 0.0760 & 0.000595 \\
\hline
\end{tabular}

Table 2: (Continued)

\begin{tabular}{|c|c|c|c|c|}
\hline Time period & $C_{r h}^{t}$ & $C_{r l}^{t}$ & $C_{e h}^{t}$ & $C_{e l}^{t}$ \\
\hline 1 & 3 & 1 & 3 & 1 \\
\hline 2 & 3.06 & 1.02 & 3.06 & 1.02 \\
\hline 3 & 3.121 & 1.040 & 3.121 & 1.040 \\
\hline 4 & 3.183 & 1.061 & 3.183 & 1.061 \\
\hline
\end{tabular}


Table 3: The input data

\begin{tabular}{|c|c|c|c|c|}
\hline \multirow{3}{*}{ Product } & Time period & $S_{\text {ns max }}^{t}$ & $B_{\text {ns max }}^{t}$ & $A C_{\text {ns max }}^{t}$ \\
\hline \multirow{3}{*}{1} & 1 & 3024836 & 1814902 & 33315 \\
\cline { 2 - 5 } & 2 & 3582189 & 2209314 & 33315 \\
\cline { 2 - 5 } & 3 & 3540994 & 1524597 & 33315 \\
\cline { 2 - 5 } & 4 & 2057449 & 1234470 & 33315 \\
\hline \multirow{3}{*}{2} & 1 & 1576850 & 946110 & 16658 \\
\cline { 2 - 5 } & 2 & 1728888 & 1097333 & 16658 \\
\cline { 2 - 5 } & 3 & 1767473 & 820484 & 16658 \\
\hline \multirow{3}{*}{3} & 4 & 1051584 & 630950 & 16658 \\
\cline { 2 - 5 } & 1 & 490177 & 294106 & 5553 \\
\cline { 2 - 5 } & 2 & 1687784 & 352670 & 5553 \\
\cline { 2 - 5 } & 3 & 622476 & 254861 & 5553 \\
\hline
\end{tabular}

Table 3: (Continued)

\begin{tabular}{|c|c|c|c|c|c|}
\cline { 3 - 6 } \multicolumn{2}{c|}{} & \multicolumn{4}{c|}{$F P R_{n s}^{t}$} \\
\cline { 3 - 6 } \multicolumn{2}{c|}{} & \multicolumn{4}{c|}{ Time period } \\
\hline \multirow{3}{*}{ Product } & Scenario & 1 & 2 & 3 & 4 \\
\hline \multirow{3}{*}{1} & $\mathrm{~L}$ & 0.1044 & 0.1078 & 0.1163 & 0.1080 \\
\cline { 2 - 6 } & $\mathrm{A}$ & 0.1044 & 0.1078 & 0.1163 & 0.1080 \\
\cline { 2 - 6 } & $\mathrm{H}$ & 0.0847 & 0.1010 & 0.1420 & 0.1017 \\
\hline \multirow{3}{*}{2} & $\mathrm{~L}$ & 0.1052 & 0.1091 & 0.1166 & 0.1098 \\
\cline { 2 - 6 } & $\mathrm{A}$ & 0.1052 & 0.1091 & 0.1166 & 0.1098 \\
\cline { 2 - 6 } & $\mathrm{H}$ & 0.0858 & 0.1029 & 0.1365 & 0.1064 \\
\hline \multirow{3}{*}{3} & $\mathrm{~L}$ & 0.1058 & 0.1097 & 0.1180 & 0.1105 \\
\cline { 2 - 6 } & $\mathrm{A}$ & 0.1058 & 0.1097 & 0.1180 & 0.1105 \\
\cline { 2 - 6 } & $\mathrm{H}$ & 0.0909 & 0.1053 & 0.1359 & 0.1080 \\
\hline
\end{tabular}

Table 3: (Continued)

\begin{tabular}{|c|c|c|c|c|c|}
\cline { 3 - 5 } \multicolumn{2}{c|}{} & \multicolumn{4}{c|}{$F A C_{n s}^{t}$} \\
\cline { 3 - 6 } \multicolumn{2}{c|}{} & \multicolumn{4}{c|}{ Time period } \\
\hline \multirow{3}{*}{ Product } & Scenario & 1 & 2 & 3 & 4 \\
\hline \multirow{3}{*}{1} & L & - & 14441 & 8756 & 14330 \\
\cline { 2 - 6 } & A & - & 14441 & 8756 & 14330 \\
\cline { 2 - 6 } & H & 16219 & 13910 & 10604 & 13827 \\
\hline \multirow{3}{*}{2} & L & - & 7127 & 4579 & 6840 \\
\cline { 2 - 6 } & A & - & 7127 & 4579 & 6840 \\
\cline { 2 - 6 } & H & 8145 & 6891 & 5445 & 6692 \\
\hline \multirow{3}{*}{3} & L & - & 2448 & 1547 & 2358 \\
\cline { 2 - 6 } & A & - & 2448 & 1547 & 2358 \\
\cline { 2 - 6 } & H & 2754 & 2313 & 1784 & 2247 \\
\hline
\end{tabular}

Table 3: Continued

\begin{tabular}{|c|c|c|c|c|}
\cline { 2 - 5 } \multicolumn{1}{c|}{} & \multicolumn{4}{c|}{$B_{n \delta}^{t}$} \\
\cline { 2 - 5 } \multicolumn{1}{c|}{} & \multicolumn{4}{c|}{ Time period } \\
\hline Product & 1 & 2 & 3 & 4 \\
\hline 1 & 907451 & 1325588 & 914758 & 340682 \\
\hline 2 & 473055 & 658400 & 492290 & 116694 \\
\hline 3 & 147053 & 211602 & 152917 & \multicolumn{3}{c}{} \\
\hline
\end{tabular}




\section{Numerical results of system dynamics (SD) simulation}

Table 4a: SD simulation's numerical results for total revenue (in GBP)

\begin{tabular}{|c|c|c|c|c|c|}
\hline \multirow[b]{2}{*}{ Time (month) } & \multicolumn{5}{|c|}{ APP strategy } \\
\hline & $\begin{array}{l}\text { The mixed chase } \\
\text { and level strategy }\end{array}$ & $\begin{array}{c}\text { The pure chase } \\
\text { strategy }\end{array}$ & $\begin{array}{c}\text { The modified chase } \\
\text { strategy }\end{array}$ & $\begin{array}{c}\text { The pure level } \\
\text { strategy }\end{array}$ & $\begin{array}{c}\text { The modified level } \\
\text { strategy }\end{array}$ \\
\hline 1 & 939.9273 & 903301 & 903301 & 939.9273 & 939.9273 \\
\hline 2 & 1705212 & 899390.3 & 899390.3 & 1163768 & 1426571 \\
\hline 3 & 824299.4 & 1085312 & 1085312 & 1163768 & 1077426 \\
\hline 4 & 1917301 & 1085312 & 1085312 & 1163768 & 1426571 \\
\hline 5 & 626718.9 & 1046242 & 1046242 & 757069.8 & 1044388 \\
\hline 6 & 1497860 & 1085312 & 1085312 & 1163768 & 1426571 \\
\hline 7 & 1530145 & 1085312 & 1101323 & 1163768 & 1086642 \\
\hline 8 & 1738581 & 1085312 & 1275443 & 1163768 & 1426571 \\
\hline 9 & 2132921 & 1085312 & 1275443 & 1163768 & 1426571 \\
\hline 10 & 735043.9 & 1085312 & 1275443 & 1163768 & 1007904 \\
\hline 11 & 1062209 & 1085312 & 1072344 & 1163768 & 1031891 \\
\hline 12 & 1176187 & 1085312 & 996416.7 & 1163768 & 1313538 \\
\hline
\end{tabular}

Table 4b: SD simulation's numerical results for total production costs (in GBP)

\begin{tabular}{|c|c|c|c|c|c|}
\hline \multirow[b]{2}{*}{ Time (month) } & \multicolumn{5}{|c|}{ APP strategy } \\
\hline & $\begin{array}{l}\text { The mixed chase } \\
\text { and level strategy }\end{array}$ & $\begin{array}{c}\text { The pure chase } \\
\text { strategy }\end{array}$ & $\begin{array}{c}\text { The modified chase } \\
\text { strategy }\end{array}$ & $\begin{array}{c}\text { The pure level } \\
\text { strategy }\end{array}$ & $\begin{array}{c}\text { The modified leve } \\
\text { strategy }\end{array}$ \\
\hline 1 & 960200 & 550933.8 & 602225.8 & 654243.6 & 797278.1 \\
\hline 2 & 834872.7 & 548533 & 566565.2 & 691454.1 & 828286.8 \\
\hline 3 & 732517.7 & 662670 & 664437.1 & 693895.8 & 669700 \\
\hline 4 & 814825.2 & 662670 & 662670 & 625579.2 & 799950.7 \\
\hline 5 & 586112.4 & 638684.8 & 638684.8 & 501150 & 669700 \\
\hline 6 & 736700 & 662670 & 665510.8 & 710116.4 & 843838.6 \\
\hline 7 & 736700 & 662670 & 669949.8 & 707879.5 & 669700 \\
\hline 8 & 736700 & 662670 & 678083.9 & 702967.6 & 851340.3 \\
\hline 9 & 802621.6 & 662670 & 662670 & 638662.1 & 826923.6 \\
\hline 10 & 736700 & 662670 & 662670 & 501150 & 669700 \\
\hline 11 & 736700 & 662670 & 654708.8 & 568710.1 & 669700 \\
\hline 12 & 736700 & 662670 & 608097.2 & 501150 & 679582.1 \\
\hline
\end{tabular}

Table 4c: SD simulation's numerical results for total labour productivity costs (in GBP)

\begin{tabular}{|c|c|c|c|c|c|}
\hline \multirow[b]{2}{*}{ Time (month) } & \multicolumn{5}{|c|}{ APP strategy } \\
\hline & $\begin{array}{l}\text { The mixed chase } \\
\text { and level strategy }\end{array}$ & $\begin{array}{c}\text { The pure chase } \\
\text { strategy }\end{array}$ & $\begin{array}{c}\text { The modified chase } \\
\text { strategy }\end{array}$ & $\begin{array}{l}\text { The pure level } \\
\text { strategy }\end{array}$ & $\begin{array}{c}\text { The modified level } \\
\text { strategy }\end{array}$ \\
\hline 1 & 0 & 0 & 0 & - & 0.03983 \\
\hline 2 & 0 & 0 & 0 & - & 0 \\
\hline 3 & 2327.808 & 1486.356 & 1486.356 & - & 0 \\
\hline 4 & 0 & 0 & 0 & - & 0 \\
\hline 5 & 0 & 0 & 0 & - & 0 \\
\hline 6 & 1838.382 & 0 & 0 & - & 0 \\
\hline 7 & 639.5527 & 0 & 0 & - & 0 \\
\hline 8 & 0 & 0 & 0 & - & 0 \\
\hline 9 & 0 & 0 & 0 & - & 0 \\
\hline 10 & 0 & 0 & 0 & - & 0 \\
\hline 11 & 0 & 0 & 0 & - & 0 \\
\hline 12 & 0 & 0 & 0 & - & 0 \\
\hline
\end{tabular}


Table 4d: SD simulation's numerical results for total costs of changes in workforce level (in GBP)

\begin{tabular}{|c|c|c|c|c|c|}
\hline \multirow[b]{2}{*}{ Time (month) } & \multicolumn{5}{|c|}{ APP strategy } \\
\hline & $\begin{array}{l}\text { The mixed chase } \\
\text { and level strategy }\end{array}$ & $\begin{array}{c}\text { The pure chase } \\
\text { strategy }\end{array}$ & $\begin{array}{c}\text { The modified chase } \\
\text { strategy }\end{array}$ & $\begin{array}{c}\text { The pure level } \\
\text { strategy }\end{array}$ & $\begin{array}{c}\text { The modified level } \\
\text { strategy }\end{array}$ \\
\hline 1 & 13.63 & 13.63 & 13.63 & - & 8.8595 \\
\hline 2 & 49471.3 & 37050.08 & 37050.08 & - & 3952.897 \\
\hline 3 & 9154.797 & 6943.752 & 6943.752 & - & 3952.897 \\
\hline 4 & 5236.825 & 11500.54 & 11500.54 & - & 3952.897 \\
\hline 5 & 9519.791 & 5262.296 & 5262.296 & - & 3952.897 \\
\hline 6 & 5948.901 & 3582.208 & 3582.208 & - & 3952.897 \\
\hline 7 & 5286.03 & 4063.28 & 4063.28 & - & 3952.897 \\
\hline 8 & 976.3848 & 2345.041 & 2345.041 & - & 3952.897 \\
\hline 9 & 3055.541 & 769.1429 & 769.1429 & - & 3952.897 \\
\hline 10 & 557.6914 & 1470.234 & 1470.234 & - & 3952.897 \\
\hline 11 & 1207.793 & 577.6719 & 577.6719 & - & 3952.897 \\
\hline 12 & 97.86914 & 275.5254 & 270.8841 & - & 3952.897 \\
\hline
\end{tabular}

Table 4e: SD simulation's numerical results for customer satisfaction

\begin{tabular}{|c|c|c|c|c|c|}
\hline \multirow[b]{2}{*}{ Time (month) } & \multicolumn{5}{|c|}{ APP strategy } \\
\hline & $\begin{array}{l}\text { The mixed chase } \\
\text { and level strategy }\end{array}$ & $\begin{array}{c}\text { The pure chase } \\
\text { strategy }\end{array}$ & $\begin{array}{c}\text { The modified chase } \\
\text { strategy }\end{array}$ & $\begin{array}{c}\text { The pure level } \\
\text { strategy }\end{array}$ & $\begin{array}{c}\text { The modified level } \\
\text { strategy }\end{array}$ \\
\hline 1 & -0.23622 & - & - & -0.23622 & -0.23622 \\
\hline 2 & 0.84524 & - & - & 0.3232 & 0.57658 \\
\hline 3 & 1 & - & - & 0.57538 & 1 \\
\hline 4 & 0.85005 & - & - & 0.76117 & 0.31435 \\
\hline 5 & 1 & - & - & 1 & 1 \\
\hline 6 & 1 & - & - & 0.42876 & 0.69381 \\
\hline 7 & 1 & - & - & 0.55945 & 1 \\
\hline 8 & 1 & - & - & 0.72223 & 0.36008 \\
\hline 9 & 0.89518 & - & - & 0.78134 & 0.64694 \\
\hline 10 & 1 & - & - & 1 & 1 \\
\hline 11 & 1 & - & - & 0.8376 & 1 \\
\hline 12 & 1 & - & - & 1 & 0.98624 \\
\hline
\end{tabular}

Table 4f: SD simulation's numerical results for total inventory holding, backordering and advertising costs (in GBP)

\begin{tabular}{|c|c|c|c|c|c|}
\hline \multirow[b]{2}{*}{ Time (month) } & \multicolumn{5}{|c|}{ APP strategy } \\
\hline & $\begin{array}{l}\text { The mixed chase } \\
\text { and level strategy }\end{array}$ & $\begin{array}{c}\text { The pure chase } \\
\text { strategy }\end{array}$ & $\begin{array}{c}\text { The modified chase } \\
\text { strategy }\end{array}$ & $\begin{array}{c}\text { The pure level } \\
\text { strategy }\end{array}$ & $\begin{array}{c}\text { The modified level } \\
\text { strategy }\end{array}$ \\
\hline 1 & 646990.4 & - & 489.6923 & 646990.4 & 646990.4 \\
\hline 2 & 117995.8 & - & 944.0911 & 449663.2 & 288680.7 \\
\hline 3 & 27416.37 & - & 1103.839 & 291515.8 & 25906.59 \\
\hline 4 & 98888.89 & - & 1119.494 & 141591.7 & 378232.3 \\
\hline 5 & 28565.54 & - & 1119.494 & 24482.63 & 25906.59 \\
\hline 6 & 32788.07 & - & 1119.494 & 419880.3 & 235502.4 \\
\hline 7 & 32788.07 & - & 1144.661 & 324587.4 & 28616.76 \\
\hline 8 & 42650.04 & - & 1144.661 & 228276.7 & 498698 \\
\hline 9 & 100642.9 & - & 1144.661 & 163302.3 & 253272 \\
\hline 10 & 55718.55 & - & 1144.661 & 41607.67 & 49491.11 \\
\hline 11 & 57565.97 & - & 1144.661 & 101256.1 & 49491.11 \\
\hline 12 & 63332.02 & - & 1144.661 & 45416.91 & 62072.2 \\
\hline
\end{tabular}


Table 4g: SD simulation's numerical results for unutilised production resources and capacity

\begin{tabular}{|c|c|c|c|c|c|}
\cline { 2 - 5 } \multicolumn{1}{c|}{} & \multicolumn{4}{c|}{ APP strategy } \\
\hline Time (month) & $\begin{array}{c}\text { The mixed chase } \\
\text { and level strategy }\end{array}$ & $\begin{array}{c}\text { The pure chase } \\
\text { strategy }\end{array}$ & $\begin{array}{c}\text { The modified chase } \\
\text { strategy }\end{array}$ & $\begin{array}{c}\text { The pure level } \\
\text { strategy }\end{array}$ & $\begin{array}{c}\text { The modified level } \\
\text { strategy }\end{array}$ \\
\hline 1 & 0.27273 & 0.42571 & 0.50927 & 0.27399 \\
0.17125 \\
\hline 2 & 0.1198 & 0.43486 & 0.46436 & 0.34059 \\
\hline 3 & 0.01243 & 0 & 0.0024 & 0.34496 & 0.21287 \\
\hline 4 & 0.09533 & 0 & 0 & 0.17483 \\
\hline 5 & 0.44751 & 0.09138 & 0.00385 & 0.37399 \\
\hline 6 & 0 & 0 & 0.00987 & 0.36999 \\
\hline 7 & 0 & 0 & 0.0209 & 0.36119 \\
\hline 1 & 0 & 0 & 0 & 0.23374 \\
\hline 11 & 0.08044 & 0 & 0 & 0.24381 \\
\hline
\end{tabular}

Table 4h: SD simulation's numerical results for total profit (in GBP)

\begin{tabular}{|c|c|c|c|c|c|}
\hline \multirow[b]{2}{*}{ Time (month) } & \multicolumn{5}{|c|}{ APP strategy } \\
\hline & $\begin{array}{l}\text { The mixed chase } \\
\text { and level strategy }\end{array}$ & $\begin{array}{c}\text { The pure chase } \\
\text { strategy }\end{array}$ & $\begin{array}{c}\text { The modified chase } \\
\text { strategy }\end{array}$ & $\begin{array}{l}\text { The pure level } \\
\text { strategy }\end{array}$ & $\begin{array}{c}\text { The modified level } \\
\text { strategy }\end{array}$ \\
\hline 1 & -1606264 & 352353.6 & 300571.9 & -1300294 & -1443338 \\
\hline 2 & 702872.6 & 313807.3 & 294831 & 22650.63 & 305650.3 \\
\hline 3 & 52882.69 & 414212.3 & 411341.3 & 178356.5 & 377866.4 \\
\hline 4 & 998350 & 411141.8 & 410022.3 & 396597.1 & 244434.8 \\
\hline 5 & 2521.125 & 402294.9 & 401175.4 & 231437.2 & 344828.6 \\
\hline 6 & 720584.7 & 419060.2 & 415099.9 & 33771.25 & 343276.8 \\
\hline 7 & 754731 & 418579.1 & 426165.4 & 131301.1 & 384372.3 \\
\hline 8 & 958254.8 & 420297.3 & 593869.5 & 232523.8 & 72579.5 \\
\hline 9 & 1226601 & 421873.3 & 610859.3 & 361803.6 & 342422.1 \\
\hline 10 & -57932.3 & 421172.1 & 610158.2 & 376026.8 & 284760.3 \\
\hline 11 & 266735.3 & 422064.7 & 415912.9 & 493801.8 & 308747.2 \\
\hline 12 & 376056.8 & 422366.9 & 386903.9 & -5875.25 & 567930.8 \\
\hline
\end{tabular}


PART 2: The system dynamics (SD) model's equations

1. Flow (rate) variable equations

1.1. New Order Inflow Rate $=$ RANDOM NORMAL $(0,1.35 e+07,8.11746 e+06$, 1.5e+06,300)*Regulating Parameter*(Advertising Costs)/(Product 1 Price + Product 2 Price + Product 3 Price) + STEP $(1.77949 e+06,2)+\operatorname{STEP}(1.77949 e+06,4)+\operatorname{STEP}(-1.77949 e+06,7)+\operatorname{STEP}(-$ 1.77949e+06, 10), Units: Item/Month

1.2. Production Rate in Regular Shift $=$ MIN (Backlog Discrepancy/Time to Correct Orders Backlog Discrepancy + Average Order Rate, Maximum Capacity in Regular Shift), Units: Item/Month

1.3. Production Rate in Extra Shift = IF THEN ELSE ((Backlog Discrepancy/Time to Correct Orders Backlog Discrepancy) + Average Order Rate > Maximum Capacity in Regular Shift, MIN ((Backlog Discrepancy/Time to Correct Orders Backlog Discrepancy) + Average Order Rate-Maximum Capacity in Regular Shift, Maximum Capacity in Extra Shift), 0), Units: Item/Month

1.4. Subcontracting Rate $=$ MIN (MAX (Backlog of Orders - Finished Products Inventory, 0)/Time to Subcontract, 3e+06), Units: Item/Month

1.5. Shipment Rate $=$ MIN (Finished Products Inventory, Backlog of Orders)/Shipment Time Units: Item/Month

1.6. Raw Materials Order Rate $=$ IF THEN ELSE (Raw Materials Inventory Discrepancy $>0$, Raw Materials Inventory Discrepancy/Time to Correct Raw Materials Discrepancy + Average Production Rate in Regular Shift*Raw Materials Used for One Item of Products + Average Production Rate in Extra Shift*Raw Materials Used for One Item of Products, Average Production Rate in Regular Shift ${ }^{*}$ Raw Materials Used for One Item of Products + Average Production Rate in Extra Shift*Raw Materials Used for One Item of Products), Units: Unit/Month

1.7. Raw Materials Arrival Rate $=$ DELAY3 (Raw Materials Order Rate, 1.5), Units: Unit/Month

1.8. Raw Materials Departure Rate $=$ Production Rate in Regular Shift*Raw Materials Used for One Item of Products + Production Rate in Extra Shift*Raw Materials Used for One Item of Products Units: Unit/Month

1.9. Hiring Rate in Regular Shift $=$ IF THEN ELSE (Regular Shift Workforce Level Discrepancy $>0$, Regular Shift Workforce Level Discrepancy/Time to Hire in Regular Shift, 0), Units: Man-Hour/Month

1.10. Hiring Rate in Extra Shift = IF THEN ELSE (Extra Shift Workforce Level Discrepancy >0, Extra Shift Workforce Level Discrepancy/Time to Hire in Extra Shift, 0), Units: Man-Hour/Month

1.11. Lay Off Rate in Regular Shift = IF THEN ELSE (Regular Shift Workforce Level Discrepancy < 0, -(Regular Shift Workforce Level Discrepancy)/Time to Lay Off in Regular Time, 0 ), Units: ManHour/Month

1.12. Lay Off Rate in Extra Shift = IF THEN ELSE (Extra Shift Workforce Level Discrepancy <0, - (Extra Shift Workforce Level Discrepancy)/Time to Lay Off in Extra Shift, 0), Units: Man-Hour/Month 
2. Stock (level) variable equations

2.1. Backlog of Orders = INTEG (New Order Inflow Rate - Fulfilled Orders), Units: Item

2.2. Finished Products Inventory= INTEG (MAX ((Subcontracting Rate + Production Rate in Extra Shift + Production Rate in Regular Shift) - Shipment Rate, 0), Units: Item

2.3. Raw Materials Inventory = INTEG (MAX (Raw Materials Arrival Rate - Raw Materials Departure Rate, 0), Units: Unit

2.4. Workforce Level in Regular Shift $=$ INTEG (MAX (Hiring Rate in Regular Shift - Lay Off Rate in Regular Shift, 0), Units: Man-Hour

2.5. Workforce Level in Extra Shift = INTEG (MAX (Hiring Rate in Extra Shift - Lay Off Rate in Extra Shift, 0)), Units: Man-Hour

2.6. Average Order Rate $=$ INTEG ((New Order Inflow Rate - Average Order Rate)/Averaging Period for Order Rate), Units: Item/Month

2.7. Average Production Rate in Regular Shift $=$ INTEG ((Production Rate in Regular Shift - Average Production Rate in Regular Shift)/Averaging Period for Production Rate in Regular Shift), Units: Item/Month

2.8. Average Production Rate in Extra Shift = INTEG ((Production Rate in Extra Shift - Average Production Rate in Extra Shift)/Averaging Period for Production Rate in Extra Shift), Units: Item/Month

\section{Auxiliary variable equations}

3.1. Advertising Costs $=$ IF THEN ELSE (Backordered Orders $>=568714,9553.45$, Advertising Equation Parameter $1+$ (Advertising Equation Parameter 2/(Advertising Equation Coefficient*Backordered Orders + Advertising Equation Parameter 3))), Units: GBP/Month

3.2. Product 1 Price $=$ IF THEN ELSE (Backordered Orders $>=339164,0.109125$, Product 1 Price Coefficient*Backordered Orders + Product 1 Price Parameter), Units: GBP/Item

3.3. Product 2 Price $=$ IF THEN ELSE (Backordered Orders $>=174744,0.110175$, Product 2 Price Coefficient ${ }^{*}$ Backordered Orders + Product 2 Price Parameter), Units: GBP/Item

3.4. Product 3 Price $=$ IF THEN ELSE (Backordered Orders $>=54806.4,0.111$, Product 3 Price Coefficient ${ }^{*}$ Backordered Orders + Product 3 Price Parameter), Units: GBP/Item

3.5. Backordered Orders = MAX (Backlog of Orders - Finished Products Inventory, 0)/Time Period, Units: Item/Month

3.6. Desired Backlog of Orders $=$ Months of Average Orders as Desired Backlog*Average Order Rate, Units: Item 
3.7. Backlog Discrepancy = MAX (Backlog of Orders - Desired Backlog of Orders, 0), Units: Item

3.8. Fulfilled Orders $=$ Shipment Rate, Units: Item/Month

3.9. Desired Raw Materials Inventory $=$ Months of Average Production in Regular Shift in Desired Raw Materials Inventory*Average Production Rate in Regular Shift*Raw Materials Used for One Item of Products + Months of Average Production in Extra Shift in Desired Raw Materials Inventory*Average Production Rate in Extra Shift*Raw Materials Used for One Item of Products, Units: Unit

3.10. Raw Materials Inventory Discrepancy = Desired Raw Materials Inventory - Raw Materials Inventory, Units: Unit

3.11. Desired Workforce Level in Regular Shift $=($ Average Production Rate in Regular Shift $*$ Months of Average Production in Regular Shift in Desired Workforce Level)*Standard Workforce Productivity in Regular Shift, Units: Man-Hour

3.12. Desired Workforce Level in Extra Shift= (Average Production Rate in Extra Shift*Months of Average Production in Extra Shift in Desired Workforce Level)*Standard Workforce Productivity in Extra Shift, Units: Man-Hour

3.13. Existing Workforce Productivity in Regular Shift Affected by Lay Off = Parameter 1 in Equation for Workforce Productivity in Regular Shift + In (Parameter 2 in Equation for Workforce Productivity in Regular Shift + Coefficient in Equation for Workforce Productivity in Regular Shift*Lay Off Rate in Regular Shift), Units: Man-Hour/Item

3.14. Existing Workforce Productivity in Extra Shift Affected by Lay Off = Parameter 1 in Equation for Workforce Productivity in Extra Shift + In (Parameter 2 in Equation for Workforce Productivity in Extra Shift + Coefficient in Equation for Workforce Productivity in Extra Shift*Lay Off Rate in Extra Shift), Units: Man-Hour/Item

3.15. Regular Shift Workforce Level Discrepancy = Desired Workforce Level in Regular Shift Workforce Level in Regular Shift, Units: Man-Hour

3.16. Extra Shift Workforce Level Discrepancy = Desired Workforce Level in Extra Shift - Workforce Level in Extra Shift, Units: Man-Hour

3.17. Newly Hired Workforce Productivity in Regular Shift = Time to Produce the First Unit of Products in Regular Shift*(Average Production Rate in Regular Shift ^ Learning Factor in Regular Shift), Units: Man-Hour/Item

3.18. Newly Hired Workforce Productivity in Extra Shift = Time to Produce the First Unit of Products in Overtime*(Average Production Rate in Extra Shift ${ }^{\wedge}$ Learning Factor in Extra Shift), Units: ManHour/Item

3.19. Total Profit $=$ Total Revenue $-($ Total Production Costs + Total Inventory Holding, Backordering and Advertising Costs + Total Costs of Changes in Workforce Level + Total Labour Productivity Costs), Units: GBP/Month 
3.20. Total Revenue $=$ Shipment Rate*(Market Share for Product $1 *$ Product 1 Price + Market Share for Product $2 *$ Product 2 Price + Market Share for Product $3 *$ Product 3 Price), Units: GBP/Month

3.21. Total Production Costs $=$ Production Rate in Regular Shift*Regular Shift Production Cost per Item + Production Rate in Extra Shift*Extra Shift Production Cost per Item + Subcontracting Rate*Subcontracting Cost per Item, Units: GBP/Month

3.22. Total Costs of Changes in Workforce Level = Hiring Rate in Regular Shift ${ }^{*}$ Cost to Hire per ManHour in Regular Shift + Lay Off Rate in Regular Shift*Cost to Lay Off per Man-Hour in Regular Shift + Hiring Rate in Extra Shift*Cost to Hire per Man-Hour in Extra Shift + Lay Off Rate in Extra Shift*Cost to Lay Off per Man-Hour in Extra Shift, Units: GBP/Month

3.23. Total Labour Productivity Costs $=($ MAX (Existing Workforce Productivity in Regular Shift Affected by Lay Off - Standard Workforce Productivity in Regular Shift, 0)*(1 - (MAX (Regular Shift Workforce Level Discrepancy, 0)/(MAX (Regular Shift Workforce Level Discrepancy, 0) + Workforce Level in Regular Shift)))*Average Production Rate in Regular Shift*Regular Shift Salary Cost) + (MAX (Existing Workforce Productivity in Extra Shift Affected by Lay Off - Standard Workforce Productivity in Extra Shift, 0)*(1 - (MAX (Extra Shift Workforce Level Discrepancy, 0)/(MAX (Extra Shift Workforce Level Discrepancy, 0) + Workforce Level in Extra Shift)))*Average Production Rate in Extra Shift* Extra Shift Salary Cost) + (MAX (Newly Hired Workforce Productivity in Regular Shift - Standard Workforce Productivity in Regular Shift, 0)*(MAX (Regular Shift Workforce Level Discrepancy, 0)/(MAX (Regular Shift Workforce Level Discrepancy, 0) + Workforce Level in Regular Shift))*Average Production Rate in Regular Shift*Regular Shift Salary Cost) + (MAX (Newly Hired Workforce Productivity in Extra Shift Standard Workforce Productivity in Extra Shift, 0)*(MAX (Extra Shift Workforce Level Discrepancy, 0)/(MAX (Extra Shift Workforce Level Discrepancy, 0) + Workforce Level in Extra Shift))*Average Production Rate in Extra Shift*Extra Shift Salary Cost), Units: GBP/Month

3.24. Total Inventory Holding, Backordering and Advertising Costs = Backordered Orders*Backordering Cost per Item + Finished Products Inventory*Finished Products Inventory Carrying Cost per Item + Raw Materials Inventory*Raw Materials Inventory Carrying Cost per Unit + Advertising Costs, Units: GBP/Month

3.25. Customer Satisfaction $=1-$ (Backordered Orders/New Order Inflow Rate), Units: Dimensionless

3.26. Unutilised Production Resources and Capacity = Subcontracting Rate/(Production Rate in Regular Shift + Production Rate in Extra Shift) + (1 - (Production Rate in Regular Shift/Maximum Capacity in Regular Shift)) + (1 - (Production Rate in Extra Shift/Maximum Capacity in Extra Shift)) , Units: Dimensionless

4. Constants

4.1. Advertising Equation Coefficient $=1$, Units: $G B P^{*}$ Month/Month ${ }^{*}$ item

4.2. Advertising Equation Parameter $1=10.2243$, Units: GBP/Month

4.3. Advertising Equation Parameter $2=1.14398 e+10$, Units: $G B P^{*} G B P /$ Month ${ }^{*}$ Month 
4.4. Advertising Equation Parameter $3=630023$, Units: GBP/Month

4.5. Averaging Period for Order Rate $=3$, Units: Month

4.6. Averaging Period for Production Rate in Extra Shift $=3$, Units: Month

4.7. Averaging Period for Production Rate in Regular Shift $=3$, Units: Month

4.8. Backordering Cost per Item $=0.075275$, Units: $G B P /$ Item

4.9. Coefficient in Equation for Workforce Productivity in Extra Shift $=1.06669 e-09$, Units: Month*Man-Hour/Man-Hour*Item

4.10. Coefficient in Equation for Workforce Productivity in Regular Shift $=1.06669 e-09$, Units: Month*Man-Hour/Man-Hour*Item

4.11. Cost to Hire per Man-Hour in Extra Shift =3, Units: GBP/Man-Hour

4.12. Cost to Hire per Man-Hour in Regular Shift = 3, Units: GBP/Man-Hour

4.13. Cost to Lay Off per Man-Hour in Extra Shift =1, Units: GBP/Man-Hour

4.14. Cost to Lay Off per Man-Hour in Regular Shift =1, Units: GBP/Man-Hour

4.15. Extra Shift Production Cost per Item $=0.0673$, Units: GBP/Item

4.16. Extra Shift Salary Cost $=0.9952$, Units: GBP/Man-Hour

4.17. Finished Products Inventory Carrying Cost per Item $=0.00066$, Units: $G B P /$ Month/Item

4.18. Learning Factor in Extra Shift $=-0.074$, Units: Dimensionless

4.19. Learning Factor in Regular Shift $=-0.074$, Units: Dimensionless

4.20. Market Share for Product $1=0.6$, Units: Dimensionless

4.21. Market Share for Product $2=0.3$, Units: Dimensionless

4.22. Market Share for Product $3=0.1$, Units: Dimensionless

4.23. Maximum Capacity in Extra Shift $=5 e+06$, Units: Item/Month

4.24. Maximum Capacity in Regular Shift $=6 e+06$, Units: Item/Month

4.25. Months of Average Orders as Desired Backlog $=1$, Units: Month

4.26. Months of Average Production in Extra Shift in Desired Raw Materials Inventory $=3$, Units: Month

4.27. Months of Average Production in Extra Shift in Desired Workforce Level $=3$, Units: Month

4.28. Months of Average Production in Regular Shift in Desired Raw Materials Inventory $=3$ Units: Month 
4.29. Months of Average Production in Regular Shift in Desired Workforce Level = 3, Units: Month

4.30. Parameter 1 in Equation for Workforce Productivity in Extra Shift $=4.55052$, Units: ManHour/Item

4.31. Parameter 1 in Equation for Workforce Productivity in Regular Shift $=4.55052$, Units: ManHour/Item

4.32. Parameter 2 in Equation for Workforce Productivity in Extra Shift $=0.0105691$, Units: ManHour/Item

4.33. Parameter 2 in Equation for Workforce Productivity in Regular Shift $=0.0105691$, Units: ManHour/Item

4.34. Product 1 Price Coefficient $=5.81577$-08, Units: $(G B P /$ Item $) *($ Month/Item $)$

4.35. Product 1 Price Parameter $=0.0894$, Units: GBP/Item

4.36. Product 2 Price Coefficient $=1.17172 e-07$, Units: Month ${ }^{*} G B P /($ Item $* /$ tem $)$

4.37. Product 2 Price Parameter $=0.0897$, Units: $G B P /$ Item

4.38. Product 3 Price Coefficient $=3.6857$ e-07, Units: Month ${ }^{*}$ GBP $/\left(\right.$ Item ${ }^{*} /$ tem $)$

4.39. Product 3 Price Parameter $=0.0908$, Units: GBP/Item

4.40. Raw Materials Inventory Carrying Cost per Unit $=0.00066$, Units: GBP/(Unit ${ }^{*}$ Month)

4.41. Raw Materials Used for One Item of Products $=0.034$, Units: Unit/Item

4.42. Regular Shift Production Cost per Item $=0.0667$, Units: GBP/Item

4.43. Regular Shift Salary Cost $=0.8654$, Units: GBP/Man-Hour

4.44. Regulating Parameter $=2.5 e-05$, Units: Dimensionless

4.45. Shipment Time $=0.9$, Units: Month

4.46. Standard Workforce Productivity in Extra Shift $=0.00075$, Units: Man-Hour/Item

4.47. Standard Workforce Productivity in Regular Shift $=0.00075$, Units: Man-Hour/Item

4.48. Subcontracting Cost per Item $=0.0745$, Units: $G B P /$ Item

4.49. Time Period $=1$, Units: Month

4.50. Time to Correct Orders Backlog Discrepancy $=0.5$, Units: Month

4.51. Time to Correct Raw Materials Discrepancy $=0.7$, Units: Month

4.52. Time to Hire in Extra Shift $=0.5$, Units: Month

4.53. Time to Hire in Regular Shift $=0.5$, Units: Month 
4.54. Time to Lay Off in Extra Shift $=0.3$, Units: Month

4.55. Time to Lay Off in Regular Time $=0.3$, Units: Month

4.56. Time to Produce the First Unit of Products in Overtime $=0.001088$, Units: ManHour*Month/Item*Item

4.57. Time to Produce the First Unit of Products in Regular Shift $=0.001088$, Units: ManHour*Month/Item*Item

4.58. Time to Subcontract $=1$, Units: Month 